\title{
Chapitre V \\ Les processus de commandes de portraits royaux
}

\section{Les mécanismes de distribution}

\section{a. Les stratégies de représentation de la cour et des élites sont interdépendantes}

La rencontre visuelle et symbolique incarnée par le portrait royal suit la rencontre réelle entre Marie-Thérèse et ses élites. Le portrait royal peut ainsi être considéré comme une métaphore de la relation et de l'échange. Les commandes de portraits royaux par Marie-Thérèse répondent aux commandes des élites. Ces divers types de transaction sont très fortement imbriqués. Les stratégies d'auto-représentation des élites interagissent avec les propres stratégies d'auto-représentation de MarieThérèse. À la légitimation de Marie-Thérèse au début du règne succède la réconciliation et la consolidation du régime au cours des décennies, autant d'étapes du règne de la souveraine. La complémentarité entre la souveraine et ses élites explique que le portrait royal soit si souvent commandé, offert et surtout exposé. La légitimité de Marie-Thérèse est le résultat d'un ensemble d'interactions, le besoin pour Marie-Thérèse de légitimer et d'être légitimée. Comme l'atteste l'exemple des abbayes autrichiennes, l'attachement aux Habsbourg est traditionnel et ne commence pas sous Marie-Thérèse.

Commander un portrait peut être comparé à un acte de reconnaissance, de remerciement et en même temps de célébration. Don diplomatique et don d'hospitalité, le portrait permet aussi une forme de légitimation. Cette reconnaissance fonctionne dans les deux sens. Si Marie Thérèse est reconnue par ceux qui commandent son portrait, elle reconnaît aussi implicitement ceux qui exposent son image. Le don de portraits par la souveraine apparaît comme un rituel qui sert de mode de gouvernement, instaurant une grande proximité entre MarieThérèse et ses sujets. Cette activité est relayée par des institutions individuelles qui commandent et achètent elles-mêmes des portraits. Le don de portraits, l'achat et les collections obéissent à des structures différentes que l'on découvre en examinant l'histoire des tableaux particuliers mais qui peuvent aussi se recouper. On achète par exemple des portraits que l'on expose ensuite dans ses collections, ou bien les portraits offerts par Marie-Thérèse sont par la suite exposés dans les salles d'exposition. 
Dans quelle mesure les modes de diffusion des tableaux renvoient-ils à différentes stratégies d'acteurs, en particulier des stratégies de représentation qui peuvent, tout en étant en rivalité, se compléter et s'entendre ? Il s'agit de décoder les motivations et les ressorts internes comme externes auxquels répondent ces commandes de portraits, les occasions au cours desquelles les portraits sont produits. La mise en parallèle des évènements politiques importants dans chaque province avec ceux de la vie et du règne de Marie-Thérèse permet de comprendre l'importance des tableaux reçus et commandés dans chaque territoire.

Le mode d'échanges et de commandes de portraits obéit à diverses logiques de mises en scène et de rivalités. La concurrence entre divers acteurs se cristallise à sa manière autour du portrait de Marie-Thérèse ${ }^{245}$. La générosité de Marie-Thérèse qui offre son portrait, ou la générosité des élites qui accueillent la souveraine de manière fastueuse lors de ses déplacements ${ }^{246}$, correspond à une manière de gouverner et une forme de pouvoir en soi, pouvoir de MarieThérèse comme des élites qui reçoivent la souveraine et les siens. Après une visite impériale, le portrait peut aussi bien être offert par Marie-Thérèse que commandé par les élites elles-mêmes.

Penchons-nous maintenant un peu plus précisément sur l'organisation de la cour sous Marie-Thérèse. L'œuvre réalisée sous le règne de Marie-Thérèse dans les domaines de la construction, de l'aménagement et de la décoration intérieure, est retranscrite dans les registres de comptes de la Chambre. La souveraine est effectivement renseignée sur toute chose et participe au financement des œuvres d'art des églises, des palais et des couvents, même si à la fin de son règne, son entourage la décharge d'un certain nombre d'activités ${ }^{247}$. Au sein de la cour, l'Obersthofmeister ${ }^{248}$, le grand maître de cour, est le plus haut responsable de l'ensemble du personnel. Il est chargé du fonctionnement de la cour ainsi que des actes du cérémoniel. Ensuite vient l'Oberstkämmerer ${ }^{249}$, le grand chambellan. Sous Marie-Thérèse, il a pour fonction de s'occuper des collections impériales des châteaux ainsi que des artistes de cour. Autre personnage important de la cour, le Kammerzahlmeister, le maître de la cour des comptes, est responsable du budget personnel du couple impérial ainsi que des dépenses exceptionnelles comme, par exemple, celles engagées pour la construction, la rénovation, et

245 Cette concurrence se déroule entre diverses villes, entre nobles, entre villes vis-à-vis des nobles, entre les ordres et états vis-à-vis du pouvoir royal de plus en plus fort.

246 C'est aussi un devoir que d'accueillir le souverain en déplacement.

247 Fleischer, Das kunstgeschichtliche Material, pp. 8-9.

248 Pangerl, « Das Obersthofmeisteramt ».

249 Pangerl, « Das Oberstkämmereramt ». 
l'aménagement des châteaux ${ }^{250}$. Les livres de comptes gérés par ce fonctionnaire sont des sources écrites primordiales ${ }^{251}$. Ces documents nous indiquent à quelle occasion la cour décide d'envoyer un portrait de Marie-Thérèse ${ }^{252}$, et à quel haut dignitaire et membre de la noblesse le portrait est destiné ${ }^{253}$. Hommage ou récompense, la commande et l'offre de portrait permettent à Marie-Thérèse de nouer des liens.

La moitié des portraits du corpus sont issus des commandes de cour. Ils sont, à proportion égale, offerts comme cadeaux ou destinés aux résidences impériales, aux universités et académies. C'est ainsi que dans les années 1750, des portraits de Marie-Thérèse sont envoyés vers les villes de Milan et Presbourg ${ }^{254}$, puis dans les années 1770 vers Tallós en Hongrie, au château de Prague, vers la résidence et l'université d'Innsbruck ${ }^{255}$. Les portraits de Marie-Thérèse répondent également à une demande locale. Les livres de comptes, inventaires et archives locales des élites de la Monarchie, certes dispersés et fragmentaires, renseignent toutefois sur les commandes de portraits par les conseils urbains mais aussi ecclésiastiques et nobiliaires ${ }^{256}$.

Offrir le portrait royal relève d'une logique de don et de contre-don qui intervient en particulier dans l'acte de donner le portrait royal. La générosité est en effet un moyen important de gouverner, un moyen aussi de mesurer une forme de popularité. C'est une façon de « se gagner les cœurs » dans une « civilisation du cœur » pour reprendre la formule de Jean Nagle afin d'établir des relations harmonieuses entre les différents partenaires sociaux et politiques ${ }^{257}$. Marie-Thérèse rend tout d'abord visite aux abbayes, puis aux villes et aux nobles. Les visites ainsi que la commande de ses portraits suivent à leur manière la chronologie des évènements politiques et personnels de son règne. D’autres

250 Fleischer, Das kunstgeschichtliche Material, p. 8.

251 Voir l'Introduction, section 2.e.

252 HHSTA HA GehKZ 1-19 HZA Nr. 19 fo. 1-161 : « auf Urlaubsaudienz ou Auf Primo Audienz », lors d'une audience de départ ou lors d'une première audience, comme par exemple lors du départ d'un ambassadeur, voir fo 56.

253 Nous citons ici un exemple de la manière dont les portraits sont « enregistrés » dans les Hofkammerzahlamts-akten : HHSTA HA GehKZ 1-19 HZA Nr. 19. 1743-1763, fo. 1-161, Listen der Geschenke, die auf kaiserlichem Befehl vom geh. Kammerzahlamt bestritten wurden. fo 16: « Zweÿ gemahlte Portraits alß Ihro Maÿtt die Königen, und Ihro König' Hochheith des H Herzogs v Lothringen und großHerzogs von Toscana, So von dem König' Cammer Mahler Meÿdens verferttigt, und Ist Ihm vor jedes obgemelter Portraits, $d ß$ anuerlangte à 40 Ducat' von dem $Z(u)$ ober Empfang abzurechnen Bewilligt worden (...) umb solche an Ihro Churfürstl. Durchl. von Cölln zuzustellen behändiget worden. ».

254 Fleischer, Das kunstgeschichtliche Material, pp. 57, 60.

255 Fleischer, Das kunstgeschichtliche Material, pp. 131-132, 134, 154, 156.

256 Fidler, « Beiträge », partie. II, pp. 205-218, partie IV, pp. 221-252.

257 Nagle, La civilisation du cœur, pp. 235-241. 
nouvelles nécessités s’imposent au fil du temps. Au portrait comme moyen et outil de reconquête succède le portrait comme moyen de gestion et de consolidation du pouvoir royal. La souveraine envoie aussi ses portraits à ses amis qui sont également de fidèles soutiens de son régime, en position d'intermédiaires par rapport aux pays, ainsi que vers des lieux censés symboliser la nouvelle emprise de l'État, comme les universités, tout particulièrement durant les quinze dernières années du règne. Dans au moins un peu plus de la moitié des cas, les tableaux sont directement commandés, à Vienne par exemple, par les élites ellesmêmes ou offerts par la souveraine aux élites. Avoir le portrait de Marie-Thérèse exposé dans sa demeure engage de fait le propriétaire, ou du moins lui impose la vue de la souveraine. De même pour les élites nobiliaires, ecclésiastiques ou citadines, la commande d'un portrait royal permet de mieux s'approprier cette figure royale. C'est un jeu d'échange qui, comme le don et le contre-don, engage les divers acteurs en présence, Marie-Thérèse, les nobles, les ecclésiastiques, les villes, au sein d'un rapport de force, apaisé par le rituel qui s'élabore autour de l'image royale.

Cet échange correspond à la mode et au goût de l'époque pour le genre du portrait et peut aussi être comparé à une volonté de contrôler et de posséder une part du pouvoir. Si les rapports de force traduisent les relations entre Marie-Thérèse et les élites, ces tensions ne concernent-elles pas aussi les élites entre elles, en compétition les unes avec les autres ? Ne s'agirait-il pas d'avoir le plus beau et le plus grand portrait de Marie-Thérèse, comme l'attestent les exemples des villes de Gand et de Bruges?

\section{b. Les modes de diffusion des tableaux relèvent de différents types de transactions}

Les portraits sont envoyés par Marie-Thérèse et la cour de Vienne à la suite de visites impériales, qui ont lieu lors d'évènements politiques et personnels. Au don répond le contre-don. Cette politique de clientélisme trouve une forme de concrétisation dans l'acte d'accueillir Marie-Thérèse, de donner, d'offrir et de recevoir le portrait royal. Un engagement s'établit alors entre les deux acteurs, entre celui qui donne et celui qui reçoit : ce dernier est souvent celui qui accueille Marie-Thérèse et reçoit ensuite son portrait, les unissant dans une relation forte. Le portrait de Marie-Thérèse instaure ainsi un rapport et un lien de réciprocité entre Marie-Thérèse et ses sujets. Aux environs de 1745, l'envoi des portraits atteint son apogée. Les principaux objectifs de la souveraine pour sa dynastie sont atteints avec le couronnement impérial de François Étienne de Lorraine. La dignité impériale est alors à nouveau entre les mains de la Maison d'Autriche. 
Lorsque les portraits sont commandés par les élites, ces commandes peuvent faire l'objet de diverses stratégies d'acteurs mais aussi d'une logique similaire du don. La commande de portraits témoigne aussi d'une forme d'auto-glorification et d'auto-représentation des élites les unes vis-à-vis des autres. Il existe plusieurs exemples d'institutions qui possèdent des portraits de Marie-Thérèse relevant des deux types de transactions et d'envois. Les portraits sont offerts par la souveraine mais ils ont aussi été commandés par les élites elles-mêmes. Nous pouvons aussi nous référer à l'exemple de l'abbaye de Lilienfeld qui reçoit un portrait de Marie-Thérèse veuve ( $\mathrm{P}$ 170, Figure 16), mais qui avait aussi commandé auparavant un portrait de la souveraine en 1756 auprès du peintre Franz Anton Palko (P 67, Figure 4) : c'était un portrait en pied majestueux destiné au réfectoire du couvent. Les portraits commandés par les états et ordres de l'époque comme par les nouveaux administrateurs de Marie-Thérèse égalent, s'ils ne dépassent même, les portraits que la souveraine commande pour ses propres appartements. Il n'est pas étonnant que les abbayes autrichiennes, connues pour leur richesse, commandent des portraits majestueux de Marie-Thérèse auprès de grands peintres, que cela soit auprès de Peter Kobler pour l'abbaye de Sankt Florian ou auprès de Franz Anton Palko pour l'abbaye de Lilienfeld. Les élites ont en effet pour habitude de s'adresser directement aux artistes, comme à l'atelier de Martin van Meytens, mais aussi auprès de peintres particuliers comme Peter Kobler, Joseph Dollenstein ou encore Daniel Schmidelli et Joseph Hauzinger.

L'acte de commander un portrait de Marie-Thérèse peut alors être lu comme une forme de démonstration de force et de représentation des commanditaires vis-à-vis du pouvoir royal comme vis-à-vis des autres élites. Inversement, lorsque Marie-Thérèse offre son portrait, de manière très régulière, il s'agit principalement d'une marque d'amitié et de récompense envers un fidèle soutien comme le sont les prieurs et abbés des grandes abbayes de la Monarchie ainsi qu'une façon de rappeler son autorité. Lors des couronnements et des cérémonies d'hommage, les visites de Marie-Thérèse, auxquelles font suite la commande et l'envoi de portraits de la souveraine, font partie d'une entreprise indispensable à la légitimation de la souveraine.

\section{Le mécanisme du don et le portrait comme forme de substitution}

Marie-Thérèse commande autant pour offrir que pour aménager ses résidences avec des collections. Les élites commandent, quant à elles, souvent pour commémorer la présence et la visite de Marie-Thérèse, tout en enrichissant de leur côté leurs propres collections. Autour de l'objet portrait, des liens particuliers se tissent 
entre Marie-Thérèse et les commanditaires ou les récepteurs des tableaux. Le don de portraits comme les voyages de Marie-Thérèse structurent les relations de la souveraine avec ses élites.

Le couronnement, ou les différents couronnements dans le cas de la Monarchie des Habsbourg ${ }^{258}$, nécessitent des déplacements et des visites auprès des élites des divers pays de la Monarchie. Marie-Thérèse est hébergée chez des nobles ou dans des couvents pendant ses voyages. Lors de son couronnement à Prague en 1743, elle est ainsi accueillie avec sa suite à l'abbaye de Melk. La même année, elle se rend aussi aux cérémonies d'hommage à Linz en HauteAutriche où elle est cette fois l'hôte de la riche abbaye de Sankt Florian.

Chaque évènement significatif de la vie et du règne du souverain est en effet célébré à l'aide de cérémonies, de rituels et de processions ${ }^{259}$. De son côté, le souverain demeure dans le château ou la villa d'un noble, dans l'abbaye d'ecclésiastiques ou dans la résidence d'un riche habitant, ces derniers mettant leurs biens à sa disposition pour l'occasion ${ }^{260}$. Marie-Thérèse ne déroge pas à la règle. Ses visites, en règle générale grandioses, sont indispensables afin de légitimer et de confirmer son pouvoir. Par sa venue, Marie-Thérèse confirme également la position de ses sujets et les honore.

À l'occasion de couronnements, de mariages ou lors de la convocation de diètes, Marie-Thérèse et François Étienne rendent visite aux plus hauts dignitaires et représentants des ordres de la Monarchie ${ }^{261}$. Après cette visite impériale, la souveraine comme les élites ont pour habitude de commander un portrait de Marie-Thérèse afin de commémorer le passage impérial. Immortalisant le moment passé ensemble, le portrait se substitue alors symboliquement à la personne de la souveraine car celle-ci demeure à sa manière présente partout. L'union directe de la reine, qui visite régulièrement ses sujets, avec ces derniers, devient concrète et manifeste, d'un point de vue matériel, avec la commande ou le don de son portrait par Marie-Thérèse. Il s'agit d'établir un lien direct et intime entre la personne qui commande et celle qui reçoit, ou entre celle qui commande et reçoit et celle qui est représentée.

258 Mentionnons le couronnement hongrois, le couronnement de Bohême et les cérémonies d'hommage autrichien ainsi que le couronnement impérial.

259 Simić, « 'Gnädiger Kaiser' und 'treuer Untertan’ », p. 39.

260 Concernant les visites de souverains comme Leopold dans leurs pays à l'occasion des cérémonies d'hommages, voir Goloubeva, The Glorification of Emperor Leopold I, p. 74. Sur la question des visites royales, voir aussi Simić, "'Gnädiger Kaiser' und 'treuer Untertan' », pp. 39-42, 39.

261 Tel est le cas pour les abbayes de Sankt Florian et de Göttweig en 1745 par exemple. 
En partant de la constatation qu'environ la moitié des portraits du corpus sont offerts ou commandés à la suite de visites et de voyages, il est possible d'affirmer que le voyage permet de résorber la distance et de rattraper le temps ou tous les moments où Marie-Thérèse ne peut être là. D’une certaine manière, il joue le même rôle que la peinture du portrait royal. Il rend, brièvement certes mais bien réellement cependant, le souverain présent. Le voyage comme le portrait comblent l'absence, occupent l'espace.

La diffusion de portraits illustre la nécessité de représenter Marie-Thérèse, au moment même où l'autorité de la Monarchie des Habsbourg est remise en question par le non-respect de la Pragmatique Sanction. Cette répartition des portraits témoigne de la proportion des personnes qui s'attribuent, et détiennent, un certain pouvoir et une importance politique qu'elles illustrent par l'achat ou l'exposition d'un portrait.

Il s’agit de légitimer la présence impériale en la commémorant et en la substituant. En tant que personnification du pouvoir et de l'État, le corps politique du souverain acquiert une valeur de permanence, d'ubiquité et d'atemporalité $e^{262}$. La mort d'une entité royale provoque cependant presque toujours une crise, au moins un changement dans l'autorité royale, dans la redéfinition de la source et de la nature de cette autorité, ne serait-ce qu'en ce qui concerne la passation de pouvoir, même si, dans le cas de Marie-Thérèse, cette dernière est censée être assurée par la Pragmatique Sanction. Affirmer de nouveau, par la démultiplication et la diffusion du portrait, la permanence du corps politique, de l'État, est alors un moyen de surmonter l'interruption provoquée par la disparition du corps naturel du précédent monarque ${ }^{263}$.

La présence des portraits dans les espaces du pouvoir et lieux de décision politique, comme les hôtels de ville, les espaces politiques et judiciaires, les espaces de pouvoir et les lieux de décision politique, à l'occasion d'évènements importants tels les couronnements, les passations et prises de pouvoir, entraîne un cérémonial précis ${ }^{264}$. Le portrait royal est alors exposé dans des salles d'au-

262 Marin, Le portrait du roi.

263 Kantorowicz, The King’s Two Bodies ; voir aussi Giesey, The Royal Funeral Ceremony ; Giesey, « Modèles de pouvoir ».

264 Martin Warnke fait allusion à la fonction des portraits en tant que substitution du personnage royal, en particulier lorsqu'il s'agit de portraits qui se trouvent dans les salles d'audience des ambassadeurs ; voir Warnke, Hofkünstler, pp. 272-273. Friedrich Polleroß donne, quant à lui, des exemples de cette fonction de substitution des portraits en particulier lors de l'hommage devant des portraits officiels dans des hôtels de ville et des salles d'audience. Il mentionne aussi l'usage du portrait dans le cadre des mariages ; voir Polleross, "Zur Repräsentation der Habsburger », pp. 87-104, p. 94. Lorne Campbell offre des exemples de substitution dans le sens 
dience sous une sorte de baldaquin. Durant toute la cérémonie, l'assistance agit en principe comme si le souverain était là en personne ${ }^{265}$.

$\mathrm{Au}$ cours de l'époque moderne, le pouvoir du portrait fait en effet l'objet de nombreuses réflexions que cela soit en littérature ou en peinture. Dans l'œuvre de Juan Batista Maino, La reconquête de Bahia (1635), le spectateur peut contempler un tableau dans le tableau. Il s'agit du portrait de Philippe IV. Maino s'inspire de l'interprétation théâtrale qu'en donne, la même année, Lope de Vega dans $E l$ Brasil restituido ${ }^{266}$. Dans cette pièce, le commandant de l'armée espagnole, Don Fadrique de Tolède, dévoile un portrait de Philippe IV devant des soldats vaincus. Il demande au monarque le pardon des prisonniers. L'image semble alors approuver de la tête ${ }^{267}$. Par leur représentation gestuelle, les soldats semblent réagir à la présence du roi présent par son image. Ils lui signifient ainsi leur reconnaissance et surtout l'acceptation de son autorité ${ }^{268}$.

De tels propos doivent toutefois être relativisés dans la mesure où les contemporains ont certainement fait la différence entre le souverain en personne et son image. Faute du roi en personne, l'exposition de son image est un substitut. L'exemple du tableau de Bahia est intéressant pour notre étude sur les portraits de Marie-Thérèse car il est possible d'interpréter les portraits comme des signes de pardon ou du moins comme des éléments participant au processus de pardon et de clémence royale. L'exemple de ce tableau où le monarque espagnol accorde sa grâce aux prisonniers est alors dans notre cas particulièrement pertinent. Marie-Thérèse est également amenée à accorder son pardon à certains sujets " infidèles ", comme en Bohême, notamment à l'évêque de Prague, Manderscheid, avec qui la souveraine tente de se réconcilier, en se rendant dans la capitale de Bohême en 1754 et 1756. S’agit-il de se réconcilier ou de réaffirmer son pouvoir ? Les deux probablement. Milde und Gerechtigkeit, Clémence et Justice, n'en demeurent pas moins des valeurs importantes pour Marie-Thérèse. Signe de pacification, les portraits de Marie-Thérèse créent une certaine unité en raison de leur nombre et de leur large distribution. Par la

contraire : des outrances au portrait royal pouvaient être punies comme si c'était le monarque lui-même qui avait été offensé ; voir Campbell, Renaissance Portraits, pp. 222-225.

265 Warnke, « Das Bild als Bestätigung », p. 504.

266 Bodart, Pouvoirs du portrait, pp. 311-312. Cet épisode parcourt toute la littérature sur le portrait; voir entre autres Pommier, « Le portrait du pouvoir », p. 11 ; Sabatier, Edouard, Les monarchies de France et d'Espagne, p. 188 ; Stoichita, « Imago Regis », pp. 181-182 ; Roeck, Das historische Auge, pp. 273-274.

267 Bodart, Pouvoirs du portrait, pp. 311-312.

268 Toutefois, dans le texte de Vega, les prisonniers répondent surtout à un ordre du général espagnol leur imposant de s’agenouiller et de se découvrir. 
démultiplication de son portrait, Marie-Thérèse apporte une forme de " paix » dans des territoires, encore récemment en guerre et occupés par des forces ennemies. On pourrait qualifier cette paix de Pax Austriaca ou encore de paix de Marie-Thérèse symbolisée par le portrait royal.

En plus de resserrer des liens d'amitié, le portrait permet de récompenser et de remercier. La souveraine remercie pour un service rendu et témoigne de sa reconnaissance à l'aide de son portrait. Les Gastgeschenke, les dons d'hospitalité, sont censés remercier de l'hospitalité rendue. Les portraits sont aussi commandés en signe de commémoration de la visite royale ou du couronnement, les visites ayant en général lieu à la suite du couronnement. Ces signes d'amitié peuvent aussi s’adresser à des émissaires étrangers, ce qui inscrit d'emblée les portraits dans un cadre diplomatique. Les portraits servent également de dons diplomatiques et de dons traditionnels d'adieu vis-à-vis de diplomates.

Pour résumer, il existe au fond trois constellations autour de la commande d'un portrait. La cour apparaît ainsi comme un acteur important de cette diffusion des portraits royaux qui souvent sont réalisés afin d'être exposés dans les palais impériaux ${ }^{269}$. Le don d'un tableau peut aussi avoir directement lieu entre la cour et différents types de destinataires ${ }^{270}$. D’autres situations enfin se déroulent où la cour n'est pas impliquée et où les nobles, abbés ou conseils urbains, commandent, de leur propre initiative, un portrait royal de Marie-Thérèse, très souvent d'ailleurs à Vienne auprès d'artistes formés à l'Académie. Ces trois catégories de commande sont relativement bien réparties, un tiers du corpus pour chaque type de diffusion. Commençons par analyser l'initiative de la cour.

\section{a. Les commandes de la cour suivies de dons : les dons d'hospitalité et les dons diplomatiques}

L'offrande de portraits est un mode de communication et de gouvernement répandu dans les milieux du pouvoir à l'époque moderne ${ }^{271}$. Marie-Thérèse n'est pas la première souveraine à offrir son portrait : cet usage est alors fort répandu. Les présents, remis lors de circonstances diverses, mariages, condoléances, naissances de princes, victoires, traités de paix, montrent la munificence et la générosité du souverain tout en étant « un moyen privilégié de diffusion de

269 Il s'agit généralement des portraits originaux.

270 Il s'agit des nobles, ecclésiastiques, villes, princes d'Empire, diplomates étrangers.

271 Concernant les différents types de portraits princiers sous forme de présents, voir Polleross, « Des abwesenden Prinzen Porträt », pp. 397-401 ; Telesko, « Herrschaftssicherung », p. 38. 
son image ", pour reprendre les termes d'Isabelle Richefort ${ }^{272}$. Dans le cas de Marie-Thérèse, les portraits se présentent sous forme de tableaux mais aussi de médaillons, de bagues et de boîtes munies de portraits en miniature de Marie-Thérèse. De nombreux types de portraits sont en effet mentionnés dans les archives ${ }^{273}$. Donner, offrir son portrait en particulier, apparaît donc comme une manière habituelle de gouvernement. Il s'agit d'un moyen très fréquent d'entretenir des relations diplomatiques, notamment vis-à-vis des pays avec lesquels on souhaite entrer ou rester en contact ${ }^{274}$.

La tradition du cadeau d'adieu et de souvenir ${ }^{275}$ remonte au début de l'époque moderne chez les Habsbourg. À la cour de Vienne, au XVI ${ }^{\mathrm{e}}$ siècle, depuis Ferdinand $\mathrm{I}^{\mathrm{er}}$ et jusque tard au cours de l'époque moderne, il est habituel d'offrir une chaîne d'or lors du départ d'un diplomate, à laquelle vient se rajouter le portrait du souverain ${ }^{276}$. Objets honorifiques, diplomatiques et politiques, le collier et le portrait permettent de manifester d'éventuels changements dans les relations politiques entre les différents pays ${ }^{277}$. De tels dons sont fréquemment utilisés par Marie-Thérèse comme en témoignent les archives viennoises ${ }^{278}$. Lorsqu'il est donné, le portrait suit un rituel, qui commence au moment même de la réception de Marie-Thérèse dans les demeures principalement aristocratiques et ecclésiastiques. Le corps physique de la reine est tout d'abord logé avec faste et pompe. Par la suite, son corps symbolique, incarné par le portrait, est conservé à l'endroit où la visite royale a eu lieu.

Abordé par les travaux de Barbara Stollberg-Rilinger ${ }^{279}$, le rituel politique est défini comme une forme de communication dans la mesure où il constitue une relation interactive entre les personnes. Les rituels, actes performatifs, créent une certaine forme de cohésion. Ils sont particulièrement utiles lorsqu'une continuité est rompue ou lorsque l'ordre est menacé ${ }^{280}$, le don du portrait royal instaure et rappelle ainsi un ordre social car le don entraîne en réponse une forme de contre-don.

272 Richefort, «Présents diplomatiques », p. 263.

273 Ces portraits sont évoqués en association avec des boîtes, des bagues ou des médaillons.

274 Durchhardt, « Das diplomatische Abschiedsgeschenk ».

275 Comme Abschiedsgeschenk ou alors als Andenken comme on peut le lire dans les archives.

276 Durchhardt, « Das diplomatische Abschiedsgeschenk », pp. 353-354.

277 Duchhardt, « Das diplomatische Abschiedsgeschenk », p. 360.

278 HHSTA HA GehKZ 1-19 HZA Nr. 19, Karton 1, fo. 1-161. HHSTA HA GehKZ 1-27 HZA Nr. 27 Karton 1, fo. 1-113.

279 Stollberg-Rilinger, « Symbolische Kommunikation», pp. 489-527.

280 Voir les propos de Stollberg-Rilinger, Rituale, pp. 9-14. 
L'ouvrage de Marcel Mauss présente ainsi l'échange de dons dans les sociétés comme des phénomènes sociaux ${ }^{281}$. S'ils apparaissent comme volontaires, les dons doivent être acceptés et faire l'objet d'un retour. Mauss distingue alors plusieurs obligations sociales fondamentales, le devoir de donner, celui d'accepter et enfin de répondre au don ${ }^{282}$. Essentielle lors de la transmission de présents, le don est aussi un instrument permettant d'établir et de rappeler des rapports de force et de hiérarchie. Celui qui reçoit se doit d'être reconnaissant tandis que celui qui donne se doit désormais d'être toujours plus généreux et surtout protecteur ${ }^{283}$. Dans le cas de Marie-Thérèse, le rituel peut être comparé à la succession d'étapes allant du voyage, à la réception de la souveraine, ainsi qu'à la manière de celle-ci de remercier. Marie-Thérèse rend ainsi visite à certains de ses sujets, ceux-ci lui accordent leur hospitalité, puis la souveraine prend congé et remercie, enfin on commande ou reçoit un portrait royal qui sert dans tous les cas à commémorer cette venue.

Le portrait de la souveraine est notamment offert par la cour à un dignitaire étranger pour son départ ou lors de la première audience d'inauguration d'un diplomate. C'est le rôle entre autres de l'Obersthofmeister, le grand maître de cour auprès de Marie-Thérèse, d'être responsable de la distribution des présents. Dans les registres de comptes de la cour, les portraits sont également recensés par l'Oberstkämmeramt, le grand chambellan. Le portrait de Marie-Thérèse est alors offert lors de l'Abschiedsaudienz ou de l'Urlaubsaudienz, autrement dit au cours de l'audience de départ des ambassadeurs ou d'une manière générale après une visite. Ce sont les principales façons pour Marie-Thérèse et sa cour d'offrir les portraits. Ceux qui sont honorés ou récompensés grâce aux portraits sont en règle générale des ambassadeurs, des nobles et des ecclésiastiques ${ }^{284}$.

Ce sont les sources écrites administratives qui nous apprennent que les portraits de Marie-Thérèse sont utilisés en tant que don ${ }^{285}$. C'est un rituel nécessaire pour entretenir de bonnes et harmonieuses relations diplomatiques avec

281 Mauss, «Essai sur le don », pp. 30-34 et pp. 50-53; voir aussi Paradis, Roy, « Le cueur craintif », p. 109.

282 Stollberg-Rilinger, Rituale, pp. 79-81, p. 79.

283 Stollberg-Rilinger, Rituale, p. 80.

284 HHSTA HA GehKZ 1-19 HZA Nr. 19, Karton 1, fo 1-161.

HHSTA HA GehKZ 1-27 HZA Nr. 27 Karton 1, fo. 1-113.

285 HHSTA HA GehKZ HZA Nr. 19 et 27. Des portraits sont très régulièrement mentionnés dans les archives, généralement sous forme de médaillons et de boîtes, ou sur des portraits en miniature comme l'atteste cette phrase qui revient si souvent « Ein Contrefaict Büchsen von Brillanten und das Porträt [. . . ] auf Urlaubsaudienz gegeben worden » ou « Auf Primo Audienz gegeben worden », une boîte et un portrait de Marie-Thérèse ont été offerts lors de l'audience de départ. 
certains pays, comme la France ou l'Angleterre, dont on espère l'aide et le soutien. Les portraits obéissent en effet à un mode de fonctionnement diplomatique et honorifique. Trois portraits de Marie-Thérèse (P 231), de son époux, l'empereur François et de la mère de Marie-Thérèse, l'impératrice-veuve Élisabeth Christine sont ainsi exposés dans la salle de dîner du château de Newby Hall dans le nord de l'Angleterre. L'ancien détenteur du château était Lord Grantham, ambassadeur d'Angleterre à la cour de Vienne ${ }^{286}$. Il aurait reçu ces trois portraits, des peintures à huile de grandes dimensions comme Abschiedsgeschenk, dons d'adieu de la souveraine pour commémorer son départ et le remercier des services rendus. Les portraits sont suspendus dans la salle de dîner. Au milieu est exposé François de Lorraine, à sa gauche, sa belle-mère, Élisabeth Christine, et à sa droite, sa femme, Marie-Thérèse. Le don, élément crucial du rituel, est l'objet de délibération comme en témoignent certaines archives, notamment les Haus-Archiv, Hofkammerzahlamtsakte. Il existe toute une économie, tout un marché du portrait ${ }^{287}$.

\section{b. La liste des cadeaux envoyés entre 1743 et 1763 sur l'ordre de la chambre des comptes}

Les dates d'envoi des portraits sont importantes, en particulier dans les années 1740, lors des couronnements de Marie-Thérèse en roi de Hongrie et de Bohême et lorsqu'il s'agit de préparer l'élection et le couronnement de François Étienne en tant qu'empereur en 1745. C'est ainsi que Meytens peint pour l'occasion deux portraits de Marie-Thérèse et de François Étienne. Pour chaque portrait envoyé au prince de Cologne, il reçoit quarante ducats. La remise d'un portrait sous forme de don résume toute cette représentation de l'acte de donner, d'échanger et de recevoir. Le présent, élément crucial du rituel, est l'objet de délibérations des autorités. C'est ainsi que le 22 juin, puis le 2 aout 1745, deux portraits de François Étienne et de Marie-Thérèse, réalisés par Martin van Meytens, sont envoyés à l'archevêque-électeur de Cologne ${ }^{288}$. François Étienne est élu le 13 septembre et couronné le 4 octobre 1745 en tant qu'empereur du Saint Empire romain germanique, sous le nom de François $\mathrm{I}^{\mathrm{er}}$.

Les dignitaires étrangers, en particulier les ambassadeurs et autres conseillers sont les premiers concernés par l'envoi de dons diplomatiques. Lors de la

286 Newby Hall \& Gardens, North Yorkshire. Nous remercions entre autres Birgit Rauscher pour ses informations sur ces portraits.

287 D’autres cadeaux ont été offerts en plus des portraits : des médailles, des diamants et des brillants, qui contenaient très souvent un portrait en miniature de Marie-Thérèse.

288 HHSTA HA GehKZ 1-19 HZA Nr. 19, Karton 1, fo. 1-161, 1743-1763, fo. 16. 
mort du ministre extraordinaire de la République de Venise à la cour viennoise, Nicolo Erizzo, à Vienne en $1746^{289}$, sa famille, ses héritiers, reçoivent un portrait de la souveraine comme cadeau, le portrait est confié au secrétaire de légation Pietro Vignola et sera remis aux héritiers du défunt à Venise ${ }^{290}$.

Dans l'énumération des tableaux, un portrait est offert à l'ambassadeur russe le 18 juillet 1752. Le portrait est ainsi donné à monsieur le comte de Bestuzev $^{291}$ après une audience de départ ${ }^{292}$. Le 17 septembre 1752, l'ambassadeur de France Emmanuel marquis d'Hautefort obtient un portrait de Marie-Thérèse pour son départ ${ }^{293}$. Il s'agit d'un contrefait avec brillant, ce qui, sans être l'objet de notre étude, mérite tout de même d'être mentionné. Les portraits sont très souvent offerts à des comtes et ambassadeurs ${ }^{294}$. Le 29 octobre 1752, l'ambassadeur du roi de Sicile et de Naples Don Pietro Peccadelli da Bologna n'est pas oublié et reçoit un portrait de Marie-Thérèse ${ }^{295}$.

Après la mort de l'empereur François $\mathrm{I}^{\mathrm{er}}$ en 1765 et le couronnement de Joseph comme empereur du Saint Empire, des portraits sous diverses formes sont de nouveau fréquemment offerts à divers ambassadeurs, comme par exemple à un nouvel ambassadeur vénitien ${ }^{296}$.

289 Nicolo Erizzo, cavaliere de Venise, est un temps ambassadeur à Vienne auprès du Saint Empire romain germanique entre novembre 1735 et décembre 1737. Il est également ambassadeur auprès de la monarchie autrichienne à Vienne entre 1744 et sa mort en 1746. Nicolo fut aussi envoyé en Espagne entre 1727 et 1729 et en Turquie entre 1739 et 1742 . Hausmann, Repertorium der diplomatischen Vertreter, pp. 412, 413, 414, 416 et 417.

290 HHSTA HA GehKZ 1-19 HZA Nr. 19, Karton 1, fo. 1-161, 1743-1763, fo. 39, relaté le 3 novembre, «den 3 November ».

291 Un Andrej Alekseevic comte de Bestuzev-Rjumin est mentionné dans le Saint Empire romain germanique en 1748, en tant qu'émissaire russe. Un autre Bestuzev, un Michail Petrovic cette fois, est quant à lui évoqué comme émissaire extraordinaire entre 1749 et 1752. C'est probablement de ce dernier qu'il s'agit dans les livres de compte de Vienne car les dates concordent. Hausmann, Repertorium der diplomatischen Vertreter, p. 317.

292 HHSTA HA GehKZ 1-19 HZA Nr. 19, Karton 1, fo. 1-161, 1743-1763, fo. 56. 18. Juli 1752 « Dem allhier an den Kaiser. König. Hof gestandenen „Russisch“ Kaiserlich Botschafter ihres Excello. Herrn Grafen Pestuchef nach dessen den 18. July. 1752 gehabter urlaubs Audienz gegeben worden. (Urlaubsaudienz oder Abschiedsaudienz) ».

293 Emmanuel marquis de Hautefort, maréchal de France, ambassadeur, prima audientia, de France dans le Saint Empire romain germanique entre 1750 et 1752. Hausmann, Repertorium der diplomatischen Vertreter aller Länder, p. 105.

294 HHSTA HA GehKZ 1-19 HZA Nr. 19, Karton 1, f ${ }^{\circ}$ 1-161, 1743-1763, fo. 56: « Den 17 Septembris 1752 ».

295 HHSTA HA GehKZ 1-19 HZA Nr. 19, Karton 1, f ${ }^{\text {o. }}$ 1-161, fo 56 : « Den 29 Octobris 1752 ».

296 Le 24 octobre 1765, l'ambassadeur vénitien Andreas Nicolo Erizzo, probablement le fils de l'ambassadeur précédent décédé en 1746, reçoit un portrait de Marie-Thérèse pour son audience de départ. HZA Nr. 27 1764-1780, fo 1-113, fo 6 et HZA Nr. 19, fo. 39. 
Ce don de portraits se fait donc vers un public intérieur, appartenant aux pays de la Monarchie, ainsi qu'extérieur, vis-à-vis des représentants des puissances étrangères. Il faut alors distinguer entre les dons de remerciement, gestes de loyauté, et les dons diplomatiques destinés à renforcer des liens diplomatiques.

Savoir mobiliser et s'appuyer sur l'affection des sujets est un aspect fondamental de la mise en place de tout État comme de toute structure et pouvoir politique, en particulier en période de crise. Ainsi, les dons donnent naissance à un véritable rituel de réciprocité. En offrant généreusement son portrait, MarieThérèse s'inscrit dans « une civilisation du cœur » selon la formule de Nagle ${ }^{297}$. La libéralité et la générosité de la souveraine entraînent une obligation très forte qui s’impose à chaque acteur de l'échange. Il s'agit de répondre au don par le contre-don, comme il a été évoqué. Le don peut correspondre à la visite de MarieThérèse, hébergée par ses élites.

Le contre-don est ensuite l'acte d'offrir et de commander le portrait royal en souvenir de ce moment passé ensemble, dans une sorte de serment direct ${ }^{298}$. La mission principale du seigneur ou du roi est d' " établir l'harmonie ", d'être « le garant de l'ordre ${ }^{299}$. Le souverain se doit « de pouvoir exercer sa faculté de donner ${ }^{300}$, à la manière d'un père protecteur ou d'une mère protectrice.

La souveraine adresse des dons à des diplomates étrangers, procédé normal durant l'époque moderne ${ }^{301}$. Lorsqu'elle offre ses portraits, la souveraine n'oublie pas non plus certaines personnalités d'importance et utiles, que cela soit les ecclésiastiques, les nobles mais aussi certains bourgeois tel le bijoutier et banquier genevois Étienne Salles. Ce dernier reçoit en 1762 un portrait de Marie-Thérèse comme don de la souveraine elle-même $(\mathrm{P} 149)^{302}$.

297 Nagle, La civilisation du cœur.

298 Nous nous appuyons notamment sur les propos de Nagle, La civilisation du cœur, pp. 236-237, p. 237 « La reconnaissance vient donc en surcroît du contre-don (...) ». Voir aussi les propos de Natalie Zemon Davis qui a étudié « le registre du don » dans la France du XVI ${ }^{\mathrm{e}}$ siècle. Zemon Davis, The Gift in sixteenth century France. Notre ouvrage travaille sur la Monarchie des Habsbourg au $\mathrm{XVIII}^{\mathrm{e}}$ siècle, autre lieu, autre époque. Toutefois, certains des propos et des logiques du don abordés par ces auteurs nous ont semblé intéressants pour comprendre les mécanismes qui lient princes et sujets au cours de l'époque moderne. Voir aussi Paradis, Roy, « Le cueur craintif », p. 106.

299 Nagle, La civilisation du cœur, p. 236 et p. 238 : « Ce lien du cœur est aussi une garantie de bon ordre $[. .]$.$» .$

300 Nagle, La civilisation du cœur, pp. 238-239, p. 239.

301 HHSTA HA GehKZ 1-19 HZA Nr. 19, Karton 1, Fol. 1-161, fo. 16, fo. 56 et fo. 39.

302 Bleeker, «Les portraits de cour », pp. 71, 80 ; Loche, « Gemälde », p. 31. Malgré l'attribution courante à la collection d'Étienne Sal(l)es, joaillier et banquier à Genève, il se pourrait que ce portrait ait plutôt été offert par Marie-Thérèse au joaillier de la cour Jean Pallard, grand-père de Mademoiselle Salles-Pallard qui légua le portrait à la Société des Arts de Genève en 1839 ; voir Loche, Roethlisberger, Liotard, vol. 1, pp. 544-545, p. 545. 
Comme nous l'avons évoqué, les relations politiques et sociales dans le royaume se construisent à partir d'un certain nombre de rituels qui structurent les entreprises de représentation de chacun, des élites comme du monarque ${ }^{303}$. Dans les années 1740, les abbayes, puis dans les années 1760 les nobles hongrois, rivalisent pour accueillir Marie-Thérèse lors de ses déplacements. Le portrait permet ainsi de commémorer un souvenir partagé. Rappelons que les cérémonies de réception vont au-delà d'une simple hospitalité pratique ${ }^{304}$.

Des portraits de Marie-Thérèse ( $P$ 136) et de François Étienne sont ainsi exposés dans les collections du château d'Eggenberg près de Graz. En route pour Innsbruck afin d'y célébrer le mariage de l'archiduc Léopold avec l'infante Marie-Louise, la famille impériale séjourne au château au cours de l'année 1765. Elle est accueillie une semaine durant dans une pompe raffinée $e^{305}$. Après ce séjour, deux portraits du couple impérial sont recensés comme Gastgeschenk, don d'hospitalité, de la souveraine envers ses hôtes, pour les remercier de leur accueil.

Le portrait apparaît ainsi comme un don, marque de commémoration mais aussi de remerciement et de récompense.

\section{c. Le portrait comme don de récompense et de remerciement}

Lorsqu'ils viennent de Marie-Thérèse et de la cour, les portraits sont donnés dans un but de récompense et de remerciement. En 1745, un peu après l'inauguration officielle de Marie-Thérèse en Brabant et en Flandre (en son absence), celle-ci envoie un portrait exécuté par Martin van Meytens au conseil de la ville de Gand. Le conseil de Flandre a en effet décidé d'offrir, en 1743, une robe de dentelle à la souveraine. Ce cadeau est destiné à Marie-Thérèse, au moment même où elle inaugure son pouvoir dans la province. Cette robe est réalisée par des Flamandes, des orphelines de la ville de Gand ${ }^{306}$, qui travaillent pendant plusieurs mois à la confection de l'habit. Les états de Flandre auraient fait réaliser cette robe de dentelle en cinq mois. Le 13 février 1744, le ministre Silva-Tarouca annonce aux états de Flandre, que la robe a bien été remise à la souveraine. Marie-Thérèse souhaite se faire peindre en portrait, vêtue de cette robe. Le peintre officiel Martin van

303 Paradis, Roy, « Le cueur craintif », pp. 120-123.

304 Sur la longue tradition des cérémonies et représentations à l'arrivée du monarque, voir Kipling, Enter the King.

305 Kaiser, Schloss Eggenberg, pp. 205, 211 et pp. 208-209 ; Wiesflecker, « Stationen », pp. 193-194.

306 Englebert, « Maria Theresia als Landesmutter der Niederlande », p. 114. 
Meytens réalise alors deux portraits. L'un d'entre eux se trouve dans la salle de cérémonie du château de Schönbrunn (P 121), le second est offert à la ville de Gand pour la salle de réception de l'hôtel de ville, où il se trouve aujourd'hui encore (P 122) ${ }^{307}$. En échange de la robe de dentelle, la souveraine remercie Gand en 1745 par l'envoi de son portrait qui la représente vêtue de cette même robe de dentelle $^{308}$. À un présent, la robe de dentelle, répond un autre présent qui prend la forme d'un portrait.

Il existe encore d'autres récits sur l'origine de certains portraits de MarieThérèse qui relèvent de cette logique du don. C'est le cas par exemple de l'abbaye cistercienne de Rein en Styrie. Elle possède un portrait (P 147, Figure 13) qui, selon la tradition, fut un cadeau de la souveraine afin de remercier l'abbaye d'avoir accueilli comme moine une personne poursuivie ${ }^{309}$. On a donc affaire encore une fois à un portrait sous forme de don et de récompense, témoignage d'un lien d'amitié.

Aux côtés des portraits recensés dans les archives viennoises, des légendes orales et des épisodes relatés dans la littérature secondaire abordent l'usage des tableaux. Nous disposons de plusieurs niveaux de recherche possibles : les archives d'époque mais aussi la manière dont les portraits de Marie-Thérèse sont demeurés dans les mémoires jusqu'à aujourd'hui, relatée par la littérature secondaire.

Ce portrait issu de l'atelier de Martin van Meytens vers la fin des années 1750 est conservé dans la bibliothèque de l'abbaye de Rein en Styrie (P 147, Figure 13). Marie-Thérèse est représentée de manière assez simple, de moitié, sans aucun attribut explicite du pouvoir, représentation habituelle lorsque le portrait est offert comme don de courtoisie et de récompense par Marie-Thérèse. Le tableau est accompagné d'une inscription commémorative : « À cause des mérites extraordinaires de Marian, abbé de Rein, envers la cour impériale, Marie-Thérèse, impératrice et reine très bienveillante », celle-ci aurait envoyé cette « effigie précieuse » d'ellemême en l'an $1768^{310}$.

Accompagné d'une chasuble, le portrait royal est offert par la souveraine. Il s'agit d'une manière ancienne de gérer ses relations pour les chefs d'État, que l'on pourrait rapprocher d'une politique clientéliste. Cette manière d'agir crée

307 Meulemeester, « Matthias de Visch », pp. 293-297.

308 Englebert, «Maria Theresia als Landesmutter der Niederlande », p. 114.

309 Hahnl, Stift Rein, p. 21. Merci au père August Janisch de l'abbaye de Rein pour ses renseignements.

310 «Ob eximia Mariani de Runa abbatis in aulam Caesaream merita Maria Theresia imperatrix ac regina clementissima [...] hanc sui effigiem pretiosam [...] transmissit anno Salutis MDCCLXVIII ». L’abbé mentionné est Marian Pittreich ; voir sur lui Mlinarič, Cistercijanska opatija Rein, pp. 124-144 ; sur Marian voir Wild, « Die Äbte von Rein », p. 58. 


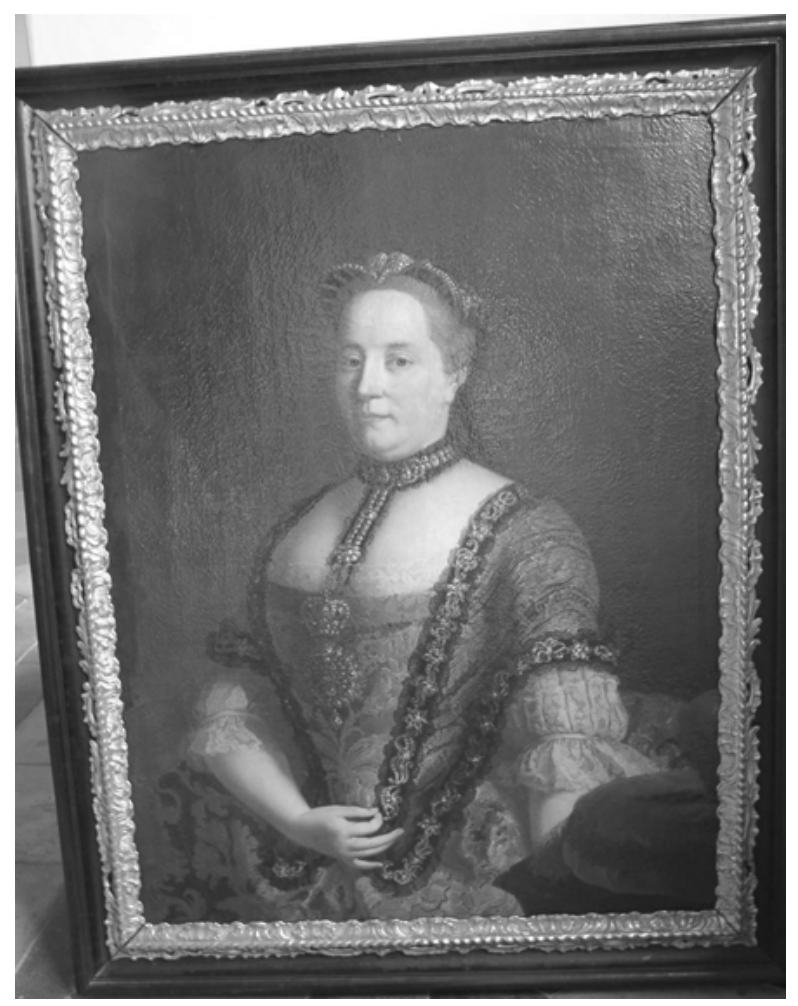

Figure 13: Atelier de Martin van Meytens, Marie-Thérèse, fin des années 1750, 100 x $70 \mathrm{~cm}$, Inv. Nr. R 455, abbaye de Rein, Autriche.

un lien très personnel, souligné par la chasuble à laquelle Marie-Thérèse a apparemment travaillé elle-même. Sous les apparences d'un acte de générosité et d'amitié, le don de portraits est un acte de pouvoir ${ }^{311}$. Offrir des portraits permet de resserrer des liens, quelle que soit la nature de ces liens : amicale, politique, économique ou autre.

Les nobles comme les ecclésiastiques ou les bourgeois sont récompensés par le don d'un portrait, en échange d'un service rendu, d'un mariage, pour la nomination à un poste, pour un départ. En 1752, le secrétaire d'État Johann Bartenstein se voit offrir des portraits royaux : on paie « deux portraits de Leurs Majestés, en pied, réalisés et livrés, avec lesquels le conseiller de cour et secré-

311 Le cas de la paire de portraits offerte par Marie-Thérèse à l'abbé Norbert II Sperges de Wilten est peut-être similaire ; voir Hammer, Die Paläste und Bürgerbauten Innsbrucks, pp. 161-162. 
taire d'État secret Johann Christoph baron de Parttenstein a été gracié, au peintre de cour impérial et royal Johann Peter Kobler ${ }^{312}$. Dans ce cas précis, un personnage de haut rang, conseiller de cour et secrétaire d'État, reçoit les portraits de Marie-Thérèse et de François Étienne en signe de reconnaissance. Aux côtés des registres de comptes de la cour, les rapports des contemporains de MarieThérèse, tel le kaiserlicher Obersthofmeister, le grand maître de cour impérial, le prince Khevenhüller, témoignent de l'usage qui est fait du portrait ${ }^{313}$. MarieThérèse s'attache ainsi une clientèle de sujets fidèles qui participent à son entreprise de légitimation ${ }^{314}$. Il est également question de récompenser le mérite ou le service rendu. Cette légitimation est réciproque car Marie-Thérèse reconnaît aussi à sa manière l'importance des personnes auxquelles elle fait don de son portrait.

En 1759, un nommé Pruckner est récompensé au moyen d'une médaille portant l'image de la souveraine. Cet ancien maître verrier de la ville morave de Lipník avait rendu des services hors du commun en guidant les troupes autrichiennes par des chemins cachés pour surprendre leurs adversaires durant le siège d'Olomouc en $1758^{315}$. Dans ce cas encore, l'image de la reine est commandée et distribuée en souvenir d'un fait passé et en récompense d'un service rendu. Objet d'échange entre Marie-Thérèse et les siens, le portrait, sur toute sa gamme de supports, permet d'apprécier les rapports entre la souveraine et ses sujets.

Dans son journal, le prince Khevenhüller raconte que madame Khevenhüller conduit une dénommée comtesse Brühl en présence de Marie-Thérèse, et celle-ci lui offre un de ses portraits, sous forme de miniature accompagné d'un bijou en forme d'aigrette. Lorsque la comtesse prend congé de la souveraine, Marie-Thérèse lui fait ses adieux en lui offrant son portrait ${ }^{316}$. Les portraits peu-

312 Fleischer, Das kunstgeschichtliche Material, p. 64: « dem K. K. Camer Mahler Johann Peter Kobler wegen 2 von Beeden K. K. Maytten in Lebensgrösse verferttigt u. geliefertten Portraiten, womit der K. K. Hof Rath und geheime Staats Secretarius Johann Christoph Freyherr von Parttenstein begnädigt worden ».

313 Khevenhüller-Metsch, Tagebuch des Fürsten Johann Joseph Khevenhüller-Metsch, Kaiserlichen Obersthofmeisters.

314 Nous sommes tout à fait conscients que le terme de "clientèle " peut être discutable. Dans les études sur le patronage, la question de savoir si la relation entre monarque et sujet peut être assimilée à celle entre patron et client, a été longtemps discutée.

315 HHSTA HA GehKZ 1-19 HZA Nr. 19, Karton 1, fo. 1-161, 1743-1763, fo.124. Den 28. July 1759.

316 Khevenhüller, Aus der Zeit Maria Theresias, 1745-1749, 1745 Febru. 8-11, p. 27: « Den 8. befande die Königin sich so gutt widerummen hergestellet, dass sie meiner Frau erlaubt, die Brühl zu ihr in die Cammer zu führen, damit sie sich beurlauben könnte; welche von der Königin Gnaden dergestalten eingenohmen worden ware, dass sie mit weinenden Augen ihren Abschied nahm. Die Königin beschenkte sie mit ihrem Porträt, so mit Brillianten en forme d'aigrette gefasst war und in einem indianischen Zupf Trigerl gelegt worden. ». 
vent aussi être offerts à l'occasion de mariages. De tels dons semblent assez habituels pour le mariage des dames de cour de l'impératrice-reine. Ainsi, le 30 octobre 1749, une boîte garnie de brillants et de l'image de Marie-Thérèse est présentée, apparemment par la souveraine elle-même, à la comtesse Maria Theresia Starhemberg qui se marie avec le baron Ferdinand Karl von Ulm ${ }^{317}$. La comtesse Auersperg reçoit un pareil cadeau de mariage (hochzeit praesent), comme la comtesse Maria Anna Trautson qui épouse le prince Johann Friedrich Lamberg ${ }^{318}$.

Des traités comme les Miroirs des Princes expliquent depuis la fin du Moyen Âge que les princes se doivent de gouverner leurs sujets avec amour et justice ${ }^{319}$. Les dons matériels et la « libéralité du cœur » exprimée par la justice et le pardon $^{320}$ constituent les deux formes principales de générosité princière, que l'on songe notamment au pardon accordé par Marie-Thérèse à certains sujets, et non des moindres, qui l'ont abandonnée au début du règne. Moyen de résoudre les conflits et d'apaiser les tensions, l'amour encadre en effet les liens sociaux et politiques au sein de la Monarchie ${ }^{321}$. C'est justement ce rapport personnel entre le monarque et ses sujets qui rend possible une politique de bon gouvernement.

\section{d. Substituer la présence royale à la suite d'une visite impériale: les visites et l'acquisition de portraits dans les abbayes}

Les portraits conservés dans les abbayes et les institutions ecclésiastiques représentent une part importante du corpus. Ces exemples ecclésiastiques sont intéressants dans la mesure où dans plusieurs cas, comme à Melk par exemple, ils présentent les deux types principaux de diffusion des portraits de MarieThérèse, comme cadeau de la souveraine elle-même et comme commande des élites, des abbés en l'occurrence.

317 HHSTA HA GehKZ 1-19 HZA Nr. 19, Karton 1, fo. 1-161, fo. 46.30 octobre 1749. Le mari, jeune noble de l'Autriche antérieure et futur président du gouvernement de cette province, est un protégé du comte Rudolf Chotek, ce qui explique vraisemblablement l'intérêt particulier de Marie-Thérèse à ce mariage; voir Quarthal, « Die vier vorderösterreichischen Regierungspräsidenten », pp. 135-136. 318 HHSTA HA GehKZ 1-27 HZA Nr. 27 Karton 1, fo. 1-113, fo 118, 28 juillet 1758, fo. 129, 5 janvier 1761. Sur l'importance sociale et politique des dames de cour et surtout de leurs mariages, voir Duindam, «Im Herzen der zusammengesetzten Habsburgermonarchie », p. 27 ; Keller, « Das Frauenzimmer », pp. 148-155. Sur le mariage de la comtesse Trautson, qui s'avéra désastreux pour la mariée, voir Bastl, Tugend, Liebe, Ehre, pp. 373, 415-416.

319 Krynen, Idéal du prince, pp. 119-123 ; Paradis, Roy, « Le cueur craintif », p. 116.

320 Paradis, Roy, « Le cueur craintif », p. 116 ; rappelons aussi que Milde und Gerechtigkeit est la devise de Marie-Thérèse.

321 Paradis, Roy, « Le cueur craintif », p. 116. 
La somptuosité est une obligation pour recevoir la famille royale, comme l'attestent les exemples de l'abbaye de Melk (P 21) et de Sankt Florian en 1743 (P 135, Figure 32) mais aussi de Göttweig en 1746 (P 96) où Marie-Thérèse et sa cour s'arrêtent à plusieurs reprises ${ }^{322}$. En respectant les lois et règles de l'hospitalité, les élites intensifient leurs liens avec leur souveraine. Une relation d'amitié, fondée une fois encore sur le don et le contre-don, se met en place. Ces échanges cachent et révèlent à la fois toute la complexité du jeu de concurrence et de rivalité, en bien des cas entre les élites elles-mêmes, comme vis-à-vis du pouvoir royal.

Ayant grand besoin d'appuis et de soutiens, Marie-Thérèse rend ainsi visite à d'éventuels supports et soutiens financiers et politiques, les deux étant liés, que cela soit dans les années 1740, 1750, ou encore 1760. C'est probablement la raison principale pour laquelle, lors des couronnements et des diètes, elle se rend si souvent chez les nobles, magistrats et abbés de ses pays qui sont autant de riches interlocuteurs ${ }^{323}$.

La souveraine doit tout d'abord être légitimée, il lui faut donc trouver rapidement des appuis. Les visites royales ont ainsi lieu auprès des abbayes autrichiennes dans les années 1740 au moment des prises de pouvoir, des cérémonies d'hommages, d'inaugurations et de couronnements. En voyage, Marie-Thérèse et sa suite séjournent alors dans les abbayes de Melk (P 21), de Sankt Florian (P 135, Figure 32), de Göttweig (P 96) ou encore de Lilienfeld (P 67, P 170, Figure 4 et Figure 16). Leur aide est indispensable à la souveraine, et réciproquement, ces abbayes ont besoin de l'aide des Habsbourg pour assurer leur position et leur mission d'évangélisation. Au fur et à mesure du règne, il est nécessaire pour Marie-Thérèse de s'assurer le soutien des dirigeants et des principaux représentants des états et des ordres. Cela reste un honneur d'accueillir la souveraine. Les abbayes sont toutes liées d'une manière ou d'une autre à la famille impériale, qu'elles soutiennent et par qui elles sont soutenues en retour. Des institutions ecclésiastiques comme Göttweig, Sankt Florian ou Melk entretiennent en effet des rapports très étroits avec la dynastie, tant avec Charles VI qu'avec MarieThérèse. Les commandes de portraits après la visite de Marie-Thérèse ${ }^{324}$ font songer à des marques d'hommage, à une série de ralliements de la part des abbayes.

En tant que riches propriétaires terriens et représentants d'un ordre important au sein des états, les établissements ecclésiastiques sont particulièrement aptes à

322 Korth et al., « Die Kaiserzimmer », p. 265; Kummer, « Abt Adrian Pliemel »; Lechner, « Göttweig », p. 810. Sur la somptuosité des réceptions, voir Paradis, Roy, « Le cueur craintif », p. 120.

323 Concernant les visites impériales et l'envoi de portraits sous forme de dons, en Serbie notamment, voir Simić, « 'Gnädiger Kaiser' und 'treuer Untertan’ », pp. 32-35, 39-42.

324 Cela peut avoir lieu lors de la cérémonie d'hommages en Haute-Autriche en 1743 ou encore après le couronnement de François Étienne en tant qu'empereur en 1745. 
commander des portraits de Marie-Thérèse. Ils n'hésitent pas à dépenser de grosses sommes d'argent pour faire réaliser d'imposants portraits de la souveraine et de François Étienne. L'exemple de Sankt Florian est particulièrement bien documenté mais il en existe d'autres dans toute l'Autriche, ou encore en Bohême et Moravie.

Des portraits de Marie-Thérèse et de François Étienne sont répertoriés aussi dans les collections de Kroměřǐž, au château de l'évêque d'Olomouc. Ces portraits sont probablement apparus sous l'évêque Troyer et sont liés aux visites du couple impérial à Kroměřǐž puis à Olomouc en 1747-1748 et en 1754 (P 56, $\mathrm{P} 57, \mathrm{P} 58)^{325}$. De même, deux grands portraits de Marie-Thérèse et de sa famille proviennent à l'origine du réfectoire d'été de l'abbaye des Prémontrés de Louka à Znojmo, Louka u Znojma, (P 143, Figure 34) ${ }^{326}$. Comme pour les couvents autrichiens, Marie-Thérèse rend visite aux couvents moraves qui représentent autant de terres de reconquête après l'occupation prussienne.

En Bohême et en Moravie tout particulièrement, Marie-Thérèse honore de sa visite les acteurs clefs de son gouvernement durant des périodes stratégiques. C'est ainsi qu'en 1743, lors du couronnement de Bohême, l'abbaye bénédictine de Břevnov près de Prague reçoit un portrait de la souveraine aux côtés de l'archiduc Joseph enfant et de la couronne de Bohême (P 77), complété par un portrait de François Étienne. À l'occasion de son passage à Prague, MarieThérèse réaffirme les privilèges de Břevnov. En contrepartie, elle attend un soutien financier de l'abbaye. Elle demande ainsi à l'abbé Benno Löbl une liste des biens qui appartiennent au couvent. Les trois quarts de ces biens, dont les pièces importantes et les bustes de reliques, sont ainsi réquisitionnés et livrés pour aider à financer les guerres menées par la souveraine ${ }^{327}$. La souveraine visite de nouveau l'abbaye lors de son passage en 1754.

À l'abbaye de Göttweig en Autriche, l'acquisition de deux portraits de MarieThérèse et de François $\mathrm{I}^{\mathrm{er}}$ est liée à la visite impériale le 19 juin 1746 (P 96). Celleci a lieu à l'occasion du jubilé de l'abbé Gottfried Bessel (1714-1749) ${ }^{328}$. L'année 1746 reste ainsi mentionnée dans les ouvrages consacrés à l'abbaye comme une date importante car elle est marquée par la visite de Marie-Thérèse, de François

325 Voir Jakubec, « 101. Portrait of Empress Maria Theresa.102. Portrait of Emperor Francis of Lorraine », pp.162-164 et Kostelnickova, « 68. Portrait of Empress Maria Theresa », pp. 110-111; Mžyková, « Kaiserin Maria Theresia ».

326 Slaviček, « Franz Anton Palko », pp. 32-41.

327 Stehliková, Le couvent de Břevnov, pp. 22-23; Preiss, Hamsíková, « Barockmalerei in Břevnov », pp. 168-200.

328 Sur Bessel, voir Coreth, « Bessel, Gottfried »; Lashofer, Profeßbuch des Benediktinerstiftes Göttweig, pp. 205-209; Lechner, Grünwald, Gottfried Bessel (1672-1749) und das barocke Göttweig; Ritter, « Gottfried Bessel als Bauherr »; Tropper, « Abt Gottfried Bessel », pp. 644-649 et pp. 653-654. 
Étienne et de son frère Charles Alexandre. Élu en 1714 abbé du monastère bénédictin de Göttweig en Basse-Autriche, Gottfried Bessel devient recteur de l'université de Vienne entre 1714 et 1716 . Au cours de la guerre de Succession d'Autriche, l'abbé, resté fidèle à la Monarchie, est l'otage des Français en 1741. Quelques années plus tard, le 19 juin 1746, il fête son jubilé de profès, de prêtre et de docteur en présence de Marie-Thérèse et de son époux à l'abbaye de Göttweig, peu après le couronnement de François Étienne en tant qu'empereur en 1745. Accueilli avec pompe par Bessel, Marie-Thérèse, rend au nom de sa mère, l'impératriceveuve Élisabeth Christine, des hommages à l'homme d'Église ${ }^{329}$.

Il s'agit donc d'un voyage, d'une visite officielle dans une ambiance fastueuse qui n'est pas sans rappeler la visite de Marie-Thérèse à l'abbaye de Melk en 1743 où de nombreux convives sont invités tel l'abbé de Göttweig. C'est un honneur de recevoir avec somptuosité la souveraine chez soi et de rivaliser dans l'accueil qui lui est fait, en hommage à la dynastie et peut-être encore plus à la personne de Marie-Thérèse.

Quelques semaines plus tard, en souvenir de sa visite à l'abbaye de Göttweig, Marie-Thérèse fait envoyer à l'abbé Bessel une croix pectorale ${ }^{330}$. C'est de l'époque de cette visite que datent les deux portraits du couple impérial ${ }^{331}$. Ils sont désormais exposés dans la salle même où la famille a séjourné dans l'abbaye.

En raison de la visite du 26 juin 1743, lors de la cérémonie d'hommage en Haute-Autriche, le prévôt de Sankt Florian Johann Georg Wiesmayr remanie, quant à lui, la salle d'audience de son abbaye. Puis, en souvenir de la visite et en commémoration du couronnement impérial de 1745, Wiesmayr fait peindre en 1746 à Vienne le double portrait de François I ${ }^{\text {er }}$ et de Marie-Thérèse pourvu d'un magnifique cadre doré. Le tableau ${ }^{332}$, exécuté par le peintre de cour Peter Kobler, est alors accroché sur le mur Sud de la salle d'audience et prend la place anciennement occupée par le baldaquin impérial, détail particulièrement symbolique ${ }^{333}$. La peinture seule revient à cent ducats ou quatre cents florins pour l'abbaye, le cadre avec la dorure et le transport à six cent vingt et un florins. Toutes les dépenses comprises, les coûts s'élèvent à mille soixante et un

329 Bessel avait en effet joué un rôle important autour des conversions au catholicisme d'Élisabeth Christine et de son grand-père, le duc de Brunswick-Wolfenbüttel ; voir Peper, Konversionen, pp. 121, 131, 147-148 ; Vašiček, Abt Gottfried Bessel, pp. 168-169.

330 Selon la lettre de remerciement de Bessel, datée du 12 juillet 1746, relatée par Vašiček, Abt Gottfried Bessel, p. 228.

331 Lechner, Grünwald, Gottfried Bessel (1672-1749) und das barocke Göttweig, p. 77; Lechner, Österreichs Glorie, pp. 40-41; Tropper, «Abt Gottfried Bessel », pp. 653-654.

332 Korth et al., « Die Kaiserzimmer », p. 275 ; voir aussi Czerny, Kunst und Kunstgewerbe, pp. 246-247; Kovács, « Maria Theresia und Franz I. Stephan ».

333 Korth et al., « Die Kaiserzimmer », pp. 265, 275. 
florins pour le couvent ${ }^{334}$. Sankt Florian offre donc un exemple d'une institution ecclésiastique prête à dépenser une somme assez considérable pour acquérir un portrait impérial en commémoration d'une visite.

Autre haut lieu ecclésiastique majeur d'un point de vue symbolique, Klosterneuburg, également surnommé l'Escurial autrichien ou le Petit Escurial, possède aussi des portraits de Marie-Thérèse et de François Étienne dans les Kaiserzimmer. Sanctuaire des reliques de Saint Léopold, patron de la BasseAutriche, l'abbaye est également le lieu de conservation du chapeau archiducal. La cérémonie d'hommage héréditaire des états de Basse-Autriche est la seule occasion au cours de laquelle le chapeau archiducal quitte le couvent. En 1730, Charles VI prend la décision de reconstruire Klosterneuburg. Pour

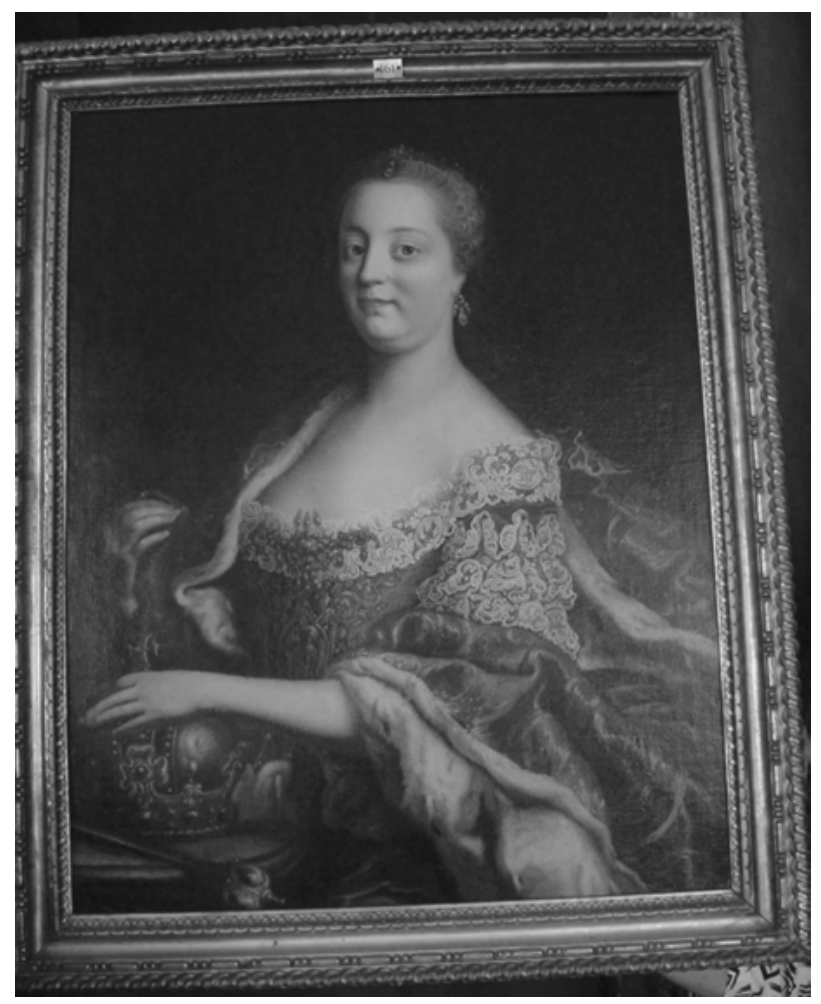

Figure 14: Atelier de Martin van Meytens, Marie-Thérèse, après 1745, 91 x $71 \mathrm{~cm}$, salle consacrée à l'empereur de l'abbaye de Klosterneuburg, Inv. Nr. GM 260, Stiftsmuseum Klosterneuburg, Autriche.

334 Czerny, Kunst und Kunstgewerbe, pp. 246-247 ; Korth et al., « Die Kaiserzimmer », p. 275. 
cela, il s'inspire du modèle du palais-monastère castillan de l'Escurial ${ }^{335}$. Toutefois après la mort de l'empereur en 1740, les travaux sont interrompus. MarieThérèse préfère le château de Schönbrunn où elle réside très fréquemment. Elle séjourne néanmoins brièvement à Klosterneuburg à plusieurs reprises dans les années $1740^{336}$; on peut dater les deux portraits d'elle (P 115, Figure 14) et de François Étienne (Figure 15), réalisés par l'atelier de Meytens, de cette époque ${ }^{337}$.

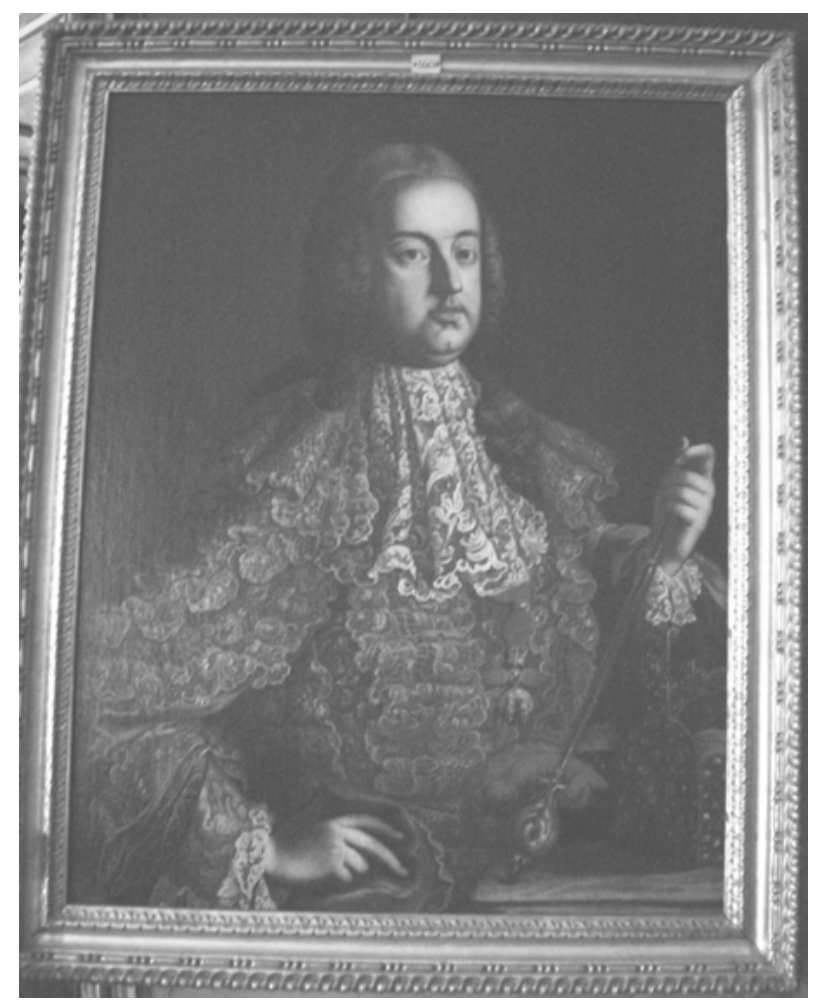

Figure 15: Atelier de Martin van Meytens, François Étienne en habit de cour espagnol, 91 x 71 cm, Inv. Nr. GM 259, Stiftsmuseum Klosterneuburg, Autriche.

335 Hassler, "Construction, fractionnement et recomposition », pp. 148-151, pp. 148-149; Huber, Stift Klosterneuburg ; Huber, Die Schatzkammer im Stift Klosterneuburg.

336 Beck, Macht-Räume Maria Theresias, p. 151: " Maria Theresia frequentierte Klosterneuburg sehr selten und blieb lediglich 1742, 1743, 1745, 1747, 1748 und 1751 über Nacht im Kloster. $\mathrm{Zu}$ diesen Gelegenheiten übernachtete sie in dem neu errichteten Trakt ihres Vaters ». Sur les visites lors du pèlerinage annuel de Saint Léopold, le 15 novembre, voir Linsboth, «Wünsche meine andacht zu verrichten », pp. 9-10.

337 Potucek, « Maria Theresia », p. 140. 
Au sein de l'abbaye cistercienne de Lilienfeld, étape où la famille impériale a pour habitude de séjourner sur la route de Mariazell, haut lieu de pèlerinage prisé par les Habsbourg, les deux portraits de Marie-Thérèse sont pour l'un, un don de Marie-Thérèse et pour l'autre, probablement une commande de l'abbaye (P 170, P 67, Figure 16 et Figure 4). Cette abbaye fidèle aux Habsbourg est occupée en 1741 par les troupes franco-bavaroises qui parcourent le pays et exigent de Lilienfeld une grosse rançon ${ }^{338}$. Afin d'assurer ce versement, l'abbé de soixante-dix-sept ans est emmené comme otage ${ }^{339}$.

Comme beaucoup d'autres demeures, l'abbaye de Lilienfeld possède une Maria-Theresien-Zimmer. La souveraine séjourne régulièrement avec d'autres membres de la Maison impériale à Lilienfeld en 1743, en 1745, dans les années 1750 et 1760. La salle où la souveraine demeure souvent et où est exposé un de ses portraits, qu'elle offre à un des abbés (l'abbé Dominique), porte depuis cette époque le nom de Maria-Theresien-Zimmer ${ }^{340}$.

Deux toiles, immenses, possédées par l'abbaye, représentant Marie-Thérèse et François Étienne en habits d'apparat, sont vraisemblablement commandées par l'abbaye de Lilienfeld elle-même auprès du peintre Franz Anton Palko, en 1756. Aujourd'hui encore, elles sont exposées dans le réfectoire d'été du couvent à côté de nombreux autres portraits des Habsbourg et Habsbourg-Lorraine, empereurs et impératrices. Ces portraits côtoient ceux de l'empereur Léopold $\mathrm{I}^{\mathrm{er}}$ et de ses épouses successives. Au sein de cette abbaye, les deux portraits royaux commandés certainement par l'institution ecclésiastique sont encore plus somptueux que les portraits offerts par Marie-Thérèse. En plus de ces majestueuses peintures, le portrait de Marie-Thérèse en veuve, représentée de moitié, est réalisé par ou selon Jean-Étienne Liotard. Ce serait un cadeau de la souveraine à l'abbé de l'époque, Dominique Peckensdorfer (ou Peckenstorfer) (P 170, Figure 16)

338 Hanthaler, Fasti Campililienses I und II; Mussbacher, Das Stift Lilienfeld.

339 Mussbacher, « Das Stift Lilienfeld », pp. 162-163.

340 Dans l'abbaye, une salle d'apparat somptueuse est ornée des portraits de nombreux souverains qui se sont montrés particulièrement généreux vis-à-vis de l'abbaye comme Rodolphe $\mathrm{I}^{\mathrm{er}}$, Albrecht I ${ }^{\mathrm{er}}$, Frédéric III, Albert II, Frédéric IV, Ferdinand II, Léopold I ${ }^{\mathrm{er}}$, Joseph $\mathrm{I}^{\mathrm{er}}$ et Charles VI. Non loin de cette salle se trouve aujourd'hui la Maria-Theresien-Zimmer où le portrait de Marie-Thérèse en veuve est exposé. Tobner, Lilienfeld, p. 366 et pp. 41-42. Concernant les Maria-Theresien-Zimmer, voir le chapitre VI.

341 Tobner, Lilienfeld, p. 42. 


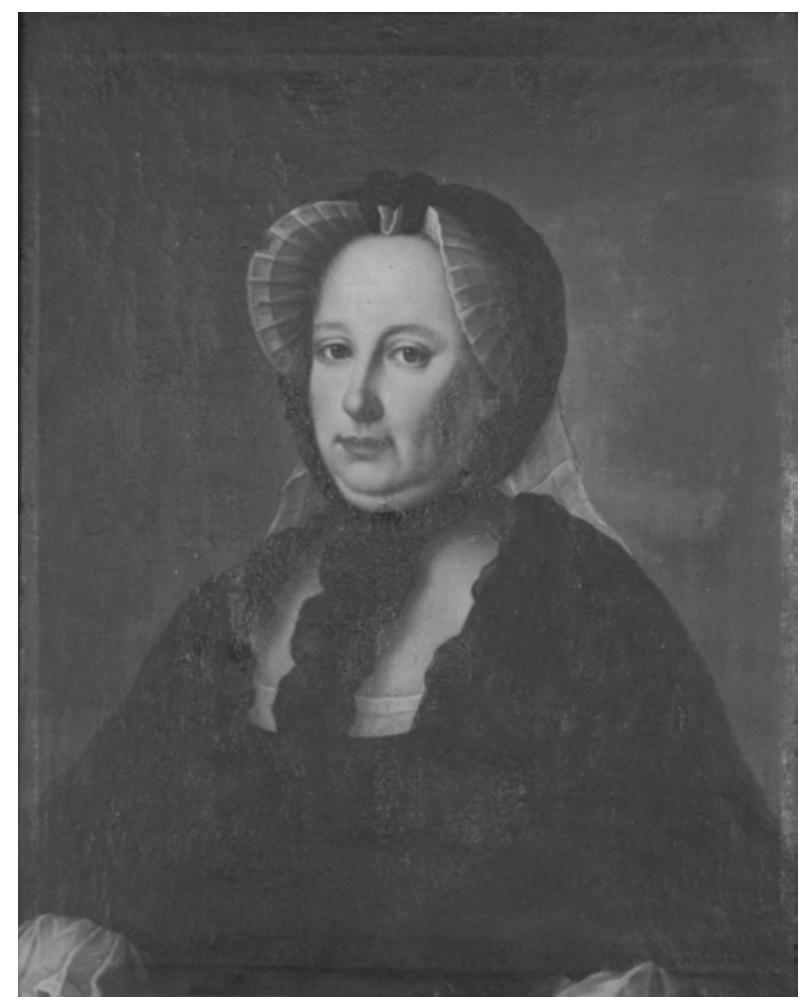

Figure 16: Jean-Étienne Liotard, Marie-Thérèse en veuve, 74 x $58 \mathrm{~cm}$, abbaye de Lilienfeld, Autriche, Stiftsarchiv, Stift Lilienfeld. Gemäldesammlung.

Enfin, parmi les monastères bénédictins, il faut mentionner l'abbaye de Melk, également en Basse-Autriche. «J'aurais regretté de ne pas y avoir été » : par cette phrase, Marie-Thérèse aurait exprimé, selon la tradition, son contentement de s'être rendue à Melk ${ }^{342}$. Deux portraits sont exposés dans cette abbaye ${ }^{343}$, proche de Vienne. Comme pour Lilienfeld, il s'agit à la fois d'une commande de l'abbaye elle-même et d'un don de portrait de la part de la souveraine (on peut du moins le supposer fortement). Les deux portraits jouent donc deux rôles distincts mais qui se rejoignent tout de même dans la représentation de Marie-Thérèse (P 21, P 13). L'un est probablement commandé par la souveraine afin de remercier

342 Ephémérides du prieur de Melk du 4 juillet 1743, cités d'après Kummer, « Abt Adrian Pliemel », p. 422 : « Es reuete mich, so ich nit hier gwesen wer».

343 Nous remercions Melk et notamment Maria Prüller pour son aide. 
l'abbé de l'hospitalité accordée (P 21) ${ }^{344}$. Pour le second tableau, la commande de l'abbaye (P 13), il s'agit plutôt de rappeler les liens avec les souverains autrichiens par le moyen d'une galerie de portraits. On fait en effet réaliser par Joseph Kremer, artiste employé régulièrement par l'abbaye, une série complète représentant tous les régents du pays en commençant par le margrave Babenberg Léopold $\mathrm{I}^{\text {er }}$ jusqu'à l'empereur Charles VI et Marie-Thérèse ${ }^{345}$.

Melk tient une grande place dans l'histoire de l'archiduché d'Autriche. La première visite de Marie-Thérèse y a lieu lors du trajet de retour de Prague, après son couronnement comme roi de Bohême en 1743. À cette époque, le couple impérial séjourne dans l'abbaye de Melk avec une suite de six cents personnes. Marie-Thérèse visitera deux fois encore l'abbaye, lors du couronnement impérial de François Étienne à Francfort en 1745 et à la fin de la guerre de Sept Ans, après le couronnement de l'archiduc Joseph en tant que roi des Romains en 1764. Le portrait, issu de l'atelier de Martin van Meytens (P 21), peut être mis en rapport avec une visite du couple impérial en 1743.

L'abbé de Melk de 1739 à 1745, Adrian Pliemel, est un puissant personnage, très proche de la famille impériale. Malgré les évènements de la guerre de Succession d'Autriche, qui entraînent même une brève occupation de l'abbaye par les troupes françaises et bavaroises, assortie du séjour de l'ennemi de MarieThérèse, Charles Albert de Bavière, en octobre 1741, l'abbé reste fidèle à la souveraine ${ }^{346}$.

$\mathrm{Au}$ début de son règne, dans une situation extrêmement difficile, MarieThérèse a un besoin urgent de subsides financiers et de soutien militaire. Elle demande même à l'ordre des prélats de Basse-Autriche de lui accorder la somme d'environ cinq cent mille Gulden. À l'occasion de la cérémonie d'hommage héréditaire, les représentants des états reçoivent, en échange, un certain nombre de présents de la part de Marie-Thérèse. Le 4 février 1741, l'ordre des prélats la remercie. L'abbé de Melk rend hommage à la souveraine pour la croix précieuse d'émeraudes et de brillants qu'elle lui a offerte, et l'assure de sa dévo$\operatorname{tion}^{347}$. Lorsqu'en 1743, Marie-Thérèse se rend à Melk pour la première fois, elle

344 Krall, " Maria Theresia als Königin von Ungarn »; Lisholm, Martin van Meytens, p. 99. Merci également à Maria Prüller pour les informations qu'elle nous a apportées.

345 Krall, « Porträts der Regenten Österreichs ». Voir aussi chapitre III.

346 Flossmann, « Geschichte des Stiftes Melk », p. 27; Otruba, « Der Feldzug », pp. 101, 106, $108-113$.

347 Kummer, « Abt Adrian Pliemel », p. 403; voir aussi Iwasaki, « Grabmal der ständischen Freiheiten », p. 324. 
est reçue en grande pompe par l'abbé ${ }^{348}$. C'est le premier voyage triomphal de la souveraine après la guerre de Succession d'Autriche.

À la suite de la cérémonie du couronnement de Bohême, le 11 mai 1743, la souveraine se dirige vers Linz afin que les états lui rendent hommage. Elle entreprend alors des séjours à Sankt Florian, Lambach ainsi que vers Steyregg. Faisant la dernière partie du voyage en bateau, elle prévoit de passer la nuit à l'abbaye de Melk, du 3 au 4 juillet 1743. C'est l'occasion pour l'abbé Pliemel de préparer les festivités et d'accueillir avec faste ses hôtes royaux ${ }^{349}$. Le maréchal du pays (Landmarschall) de Basse-Autriche fait savoir à l'abbé Pliemel que la reine projette de passer la nuit dans le couvent, après la cérémonie d'hommage à Linz. Le maréchal somme l'abbé de venir à une audience royale dans le but d'inviter Marie-Thérèse, ce que Pliemel ne manque pas de faire. La souveraine accepte gracieusement l'invitation que son fonctionnaire, le maréchal du pays, vient de solliciter ${ }^{350}$. Cet évènement bien documenté nous offre un exemple des dimensions matérielles et symboliques de la relation étroite entre la dynastie et les établissements ecclésiastiques de la Monarchie.

La Pietas Austriaca correspond à un projet commun aux Habsbourg et aux ecclésiastiques, révélant fondamentalement un besoin réciproque d'entraide. Le rôle politique de première importance des couvents explique l'attention que leur portent les Habsbourg, en particulier Marie-Thérèse. Beaucoup de portraits conservés dans les grands couvents des provinces autrichiennes de la Monarchie $^{351}$ sont commandés par les abbés aux alentours de 1745 , date du couronnement de François Étienne en tant qu'empereur, après une visite impériale.

L'exemple des soutiens ecclésiastiques peut aussi bien s'appliquer à d'autres types de sujets comme les nobles, qu'il s'agisse des vieilles familles ou encore de serviteurs clefs plus récemment élevés dans la hiérarchie. Les visites stratégiques que Marie-Thérèse rend aux abbayes autrichiennes comme aux nobles hongrois et de Bohême dans les années 1740, 1750 et 1760 montrent l'intérêt de la souveraine à s'attacher le soutien de ses élites, et inversement l'intérêt des élites à soutenir Marie-Thérèse. En Bohême et en Moravie, les portraits sont commandés par les élites locales dans les années 1740, lors des visites de Marie-Thérèse, puis envoyés par la cour dans les années 1750. En 1754, la réconciliation, ou la tentative de réconciliation, de la souveraine avec l'archevêque de Prague fut aussi l'occasion de rendre visite à des abbayes comme celle de Břevnov.

348 Kummer, « Abt Adrian Pliemel », pp. 417-422.

349 Kummer, « Abt Adrian Pliemel », pp. 410-411.

350 Kummer, " Abt Adrian Pliemel », p. 410.

351 Melk, Klosterneuburg, Schlägl, Seitenstetten, Lilienfeld, Sankt Florian, Göttweig. 


\section{Commandes des élites et évènements politiques, faisant souvent suite aux visites}

Les portraits sont commandés en souvenir de la présence royale, ou dans l'attente de cette visite. C'est une manière de garder en mémoire la présence de la souveraine et de satisfaire un besoin de présence royale. Appuyons-nous sur des exemples précis. Le Musée régional d'Olomouc conserve un assez petit portrait de Marie-Thérèse réalisé en 1748. En juin 1748, le couple impérial se rend en effet à Olomouc. En dehors de la forteresse nouvellement construite, le couple impérial visite aussi le couvent prémontré de Hradisko et le Svatý Kopeček, chapelle de pèlerinage qui appartient à l'abbaye de Hradisko. Ce portrait de la souveraine, âgée alors de trente-et-un ans, est commandé par le magistrat de la cité royale Simon Tadeas Josef Zimmerle au moment même de la visite impériale $^{352}$. Le portrait commandé par la ville est vraisemblablement lié à cette visite de Marie-Thérèse, demandé comme il est d'usage après ou pour une visite impériale, en souvenir de cette rencontre (P 30).

Cette commande est aussi une marque de soutien du magistrat en faveur des Habsbourg-Lorraine, plus précisément en faveur de Marie-Thérèse, aussi bien qu'un geste d'auto-représentation de la ville d'Olomouc, cité morave occupée par les Prussiens en 1741, fidèle en début de règne à la Monarchie contrairement à Prague cité de Bohême. Signe politique en Moravie, les portraits le sont aussi dans le royaume de Saint Étienne.

En Hongrie, les diètes ont lieu en 1741, 1751 et 1764, moments politiques cruciaux dont profite Marie-Thérèse pour rendre visite à ses élites. Les visites royales ainsi que l'envoi de portraits apparaissent comme des moyens d'apaisement et d'intégration dans l'ensemble monarchique, durant des périodes marquées notamment par le besoin d'argent de la souveraine et de la Monarchie. Marie-Thérèse, ou des membres de la famille impériale, se rendent alors auprès de personnages et d'institutions clefs, et surtout fortunés, de la Monarchie.

D'une manière générale, les destinations hongroises, assez proches de Vienne et de Presbourg, sont les plus prisées par Marie-Thérèse. Seuls deux voyages sont recensés au cours desquels Marie-Thérèse s'avance plus loin à l'intérieur du pays : l'un a lieu en 1751 vers Gödöllö, près de Buda, auprès du comte Grassalkovich, et l'autre en 1764 vers Vác, auprès de Christophe Antoine Migazzi, autrement dit lors des deux dernières diètes hongroises ${ }^{353}$. Il s'agit, du

352 Merci à Jaroslava Kunzfeldová d'avoir bien voulu nous ouvrir les dossiers du Musée d'Olomouc.

353 À Vác, l'unique arc de triomphe est commandé par l'évêque Migazzi en 1764 auprès de l'architecte Canevale, en l'honneur de Marie-Thérèse, à l'occasion de la visite de celle-ci lors 
moins pour Grassalkovich, d'un nouveau confident et conseiller très proche de la souveraine, récemment élevé en raison de sa relation personnelle avec MarieThérèse. Celle-ci lui rend visite à son château de Gödöllő lors de son voyage à Buda, qui a pour but d'encadrer et d'apprécier la rénovation du palais royal de la capitale hongroise ${ }^{354}$. C'est un moment exceptionnel car depuis 1526, date de l'acquisition de la Hongrie, aucun souverain Habsbourg n'a résidé à Buda. Rappelons que la ville est restée sous le contrôle de l'Empire ottoman jusqu'en 1680, date où la ville a été reconquise ${ }^{355}$.

De son côté, Grassalkovich vient de faire construire un magnifique château, Gödöllo", près de Buda, espérant ainsi pouvoir accueillir sa souveraine. Grassalkovich illustre bien la relation familière entre la souveraine et certains grands, en particulier ceux qu'elle a elle-même élevés, pour les remercier de leur fidélité et de leur dévouement. Antal Grassalkovich I ${ }^{\mathrm{er}}(1694-1771)^{356}$ joue un rôle important dans l'histoire hongroise comme dans celle de la Monarchie. Gardien de la couronne, il est le représentant de la souveraine en Hongrie. Lors de la rencontre de 1751 entre le comte et Marie-Thérèse, la souveraine attend tout naturellement de Grassalkovich qu'il défende ses intérêts à la diète qui est alors en train de se dérouler ${ }^{357}$.

Entre le 10 et le 12 août 1751, Grassalkovich reçoit de manière princière Marie-Thérèse dans son château de Gödöllö ${ }^{358}$. Pour cette visite, le comte Anton fait aménager une chambre dans le château, richement décorée afin d'accueillir sa souveraine comme il se doit, de manière digne d'une souveraine, mais aussi comme une amie. Cette pièce correspond à l'actuelle Maria-Theresien-Zimmer de la résidence, où est maintenant exposé un portrait de Marie-Thérèse en roi de Hongrie (P 229), acquis par le château en 2010, et qui remplace un portrait similaire de la souveraine accroché dans cette pièce au XVIII ${ }^{\mathrm{e}}$ siècle et disparu au cours du XX ${ }^{\mathrm{e} 359}$. Aujourd'hui les portraits conservés au château de Gödöllő sont les portraits P 102, P 146 et P 229 de la liste.

de la dernière diète, qui vise principalement à apaiser les insatisfactions croissantes des nobles, concernant notamment l'augmentation des impôts ; Vajdai et Varga, Maria Theresia in Gödöllő, p. 10 et p. 14.

354 Vajdai et Varga, Maria Theresia in Gödöllö, p. 10.

355 Vajdai et Varga, Maria Theresia in Gödöllo", p. 31.

356 Fallenbüchl, Anton Grassalkovich; Evans, « Maria Theresia and Hungary », p 191.

357 Par la suite, sous le règne de l'empereur François Joseph, le château de Gödöllő est offert par les Grassalkovich à la famille impériale.

358 Vajdai et Varga, Maria Theresia in Gödöllo", p. 21, p. 33, pp. 36-38.

359 Merci à János Papházy. 
De nombreuses légendes se rattachent à la visite de la souveraine à Gödöllő. L'une d'entre elles, probablement la plus connue, légende particulièrement charmante dans le cadre d'une étude sur les portraits, est restée sous la désignation $\mathrm{du}$ " compliment du comte ». On raconte que Marie-Thérèse ne vit qu'un défaut au palais, le manque de tableaux :

Mon cher Comte, dit-elle, ne vous semble-t-il pas, cela manque de tableaux un peu ? C'est bien cela, je m'en suis aperçu moi-même, répondit le Comte, mais aucun tableau ne me paraissait digne d'être placé chez moi, tant que le portrait de ma reine n'ornât pas ma demeure. [...]

Dès qu'elle rentra à Vienne, elle offrit son portrait et celui de son époux au Comte. Ce fut le peintre Jean-Étienne Liotard qui réalisa ces portraits ${ }^{360}$

De tels épisodes légendaires rendent compte de l'enjeu du portrait comme élément de reconnaissance entre la souveraine et ses élites. Il importe au fond peu que cela se soit précisément déroulé de cette manière, le fait même qu'on ait eu intérêt à faire circuler un tel récit en dit long sur la signification que l'on prête au portrait de Marie-Thérèse.

Les multiples visites de la souveraine auprès des nobles hongrois peuvent être mises en parallèle avec l'apparition de portraits royaux dans les demeures nobles hongroises comme chez les Pálffy et les Esterházy, qui datent aussi de cette époque, dans les années 1750, 1760 et 1770.

Grâce aux nombreux châteaux construits et rénovés au cours du XVIII ${ }^{\mathrm{e}}$ siècle au sein du royaume de Hongrie, les nobles hongrois, qui ne cessent de rivaliser entre eux, cherchent à s'intégrer dans la structure monarchique tout en préservant leurs libertés. Pour certains, ce déploiement architectural correspond à un espoir et une attente d'une visite royale, occasion de se hisser audessus de ses pairs et de laisser une impression favorable chez la souveraine. Celle-ci restaure en effet des années 1750 aux années 1770 ses propres résidences royales et met en place ses propres galeries familiales ${ }^{361}$.

Encore plus que Buda, qui est relativement éloignée de Vienne, Presbourg est l'un des grands centres privilégiés par Marie-Thérèse, proche de la capitale autrichienne et facile d'accès. Non loin de Vienne, la souveraine visite ainsi fréquemment la haute noblesse hongroise dans ses châteaux. Elle y rencontre notamment les membres de la famille Esterházy. Avant d'atteindre Vác et Buda en

360 Vajdai, Varga, Maria Theresia in Gödöllo", p. 38 et p. 44; voir aussi Galavics, «A 'képtelen Gödöllő’ és más történetek »; Vajdai, Maria Theresia in Gödöllő, pp. 22-23. Ce récit ressemble beaucoup à une composition du XIX ${ }^{\mathrm{e}}$ siècle, il nous a toutefois semblé intéressant de le mentionner.

361 Voir chapitre VI. 
1765, Marie-Thérèse passe rapidement dans les châteaux Esterházy de Tallós ${ }^{362}$, Köpcseny et de Karalyfa. Elle fête même son anniversaire le 13 mai 1766 au château de Csekleszar, aujourd'hui Bernolákovo, chez le chancelier comte Ferenc Esterházy ${ }^{363}$.

Ces rencontres inscrivent la politique et le mode de gouvernement de MarieThérèse dans une tradition personnalisée de gouvernement puisque la venue de la souveraine est suivie de l'envoi de portraits. Tout cela se fait sur un mode politique et amical rappelant l'union des monarques avec leurs sujets. Ces voyages et ces rencontres ne se limitent pas à la Hongrie mais concernent aussi la Bohême.

Lors du voyage de 1754, Marie-Thérèse rend visite à certaines grandes personnalités de Bohême comme le comte Chotek à Veltrusy et l'archevêque Manderscheid, déjà mentionné plus haut. Cela semble attester que ce voyage est entrepris dans l'objectif d'une réconciliation, l'un comme l'autre ayant favorablement accueilli Charles Albert en 1741. Le but est d'entretenir de bons rapports avec les personnalités majeures de ces territoires indispensables à la couronne d'un point de vue politique, mais aussi économique, et qui ont été envahis ou occupés pendant plusieurs années par les troupes étrangères au début du règne. Beaucoup plus intégrée au noyau autrichien que la Hongrie, la Bohême est dans une position difficile et tendue vis-à-vis du pouvoir central viennois. Toutefois, la Moravie, plus proche de Vienne que de Prague même, est aussi plus favorable aux Habsbourg que le royaume de Bohême traditionnellement plus autonome et plus attaché à ses libertés.

Marie-Thérèse espère longtemps récupérer la Silésie, région riche d'un point de vue économique et commercial, dont la perte doit être compensée par la mise en valeur d'autres territoires. En effet, si les déplacements de la souveraine se déroulent lors d'occasions politiques, elles s'inscrivent aussi dans un cadre économique. Lors de sa visite en 1754 à Veltrusy au nord de Prague, demeure de la famille Chotek, Marie-Thérèse prend part à l'exposition des industries de Bohême, Gewerbeausstellung, manière de rappeler l'importance manufacturière ${ }^{364}$ des pays de la couronne de Bohême. Rudolf Chotek détient alors des postes clés dans l'administration des finances et du commerce. En effet, si les frères Chotek ont reconnu Charles Albert de Bavière alors qu'il était à Prague, ils sont très vite

362 Fleischer, Das kunstgeschichtliche Material, p. 154: « Vor Portraits des Kayszers und Kayszerin nach Tallosch in hungarn samt Rahmen ». Ce tableau n'est pas forcément à mettre sur le compte de la visite de 1764 et en réalité, on ne sait pas exactement où à Tallosch ce portrait était destiné.

363 Vajdai, Maria Theresia in Gödöllö, pp. 13-17, p. 16.

364 Klíma, «Industrial Growth »; Klíma, « Probleme der Proto-Industrie ». 
revenus auprès de Marie-Thérèse, qui les a élevés au rang de comtes en $1745^{365}$. Le château de Veltrusy conserve depuis lors plusieurs portraits en pied du couple impérial (P 114) ${ }^{366}$.

$\mathrm{Au}$ même moment, Marie-Thérèse se rend à Prague pour tenter de se réconcilier, tant bien que mal, avec l'archevêque de Prague, Johann Moritz Gustav von Manderscheid, alors que ce dernier s'était rallié à Charles Albert de Bavière au début des années $1740^{367}$. Marie-Thérèse tente ainsi, avec plus ou moins de succès, de transformer d'anciens opposants en fidèles piliers du régime. Plus qu'en simple signe d'assentiment vis-à-vis du pouvoir en place, certains individus, et non des moindres, ont un intérêt à exposer les portraits de la famille impériale pour faire oublier des épisodes de désunion au début du règne. C'est aussi une manière pour eux comme pour les grandes familles de prétendre au pouvoir. Marie-Thérèse peut alors se montrer magnanime pour renforcer l'étendue de sa souveraineté.

Marie-Thérèse essaie de faire participer au gouvernement, et notamment à la visite des royaumes, son époux, qu'elle nomme corégent en 1741, ainsi que toute sa famille. Parmi ces visites, évoquons celle qui a lieu entre les 3 et 13 juin 1751. François Étienne et l'archiduc Joseph visitent les très riches villes minières et les mines de l'ancienne Hongrie royale, actuellement en Slovaquie, à Banská Štiavnica notamment, satisfaisant entre autres l'intérêt personnel de François Etienne pour les mines et les monnaies ${ }^{368}$. Toute la famille impériale se partage en effet les visites au sein du royaume de Hongrie.

À la suite de cette visite, ou en raison de la visite impériale, le président du Münz- und Bergwesens-Directions-Hofcollegium, la direction des mines à Vienne, Karl Ferdinand Königsegg comte de Rothenfels-Erps ${ }^{369}$, commande

365 Rudolf Chotek était depuis 1749 président de la Ministerial-Banco-Deputation et du Commercien- Oberdirectorium, avant de devenir président de la Hofkammer en 1759 et chancelier de la Böhmisch- österreichische Hofkanzlei en 1762. Johann Karl Chotek avait été nommé chancelier du Directorium in publicis et cameralibus en 1753, ce qui faisait de lui le deuxième homme de cette institution après Haugwitz ; voir Cerman, "Opposition oder Kooperation », pp. 381-382 ; Hackl, "Chotek »; Hochedlinger, « Die Maria-Theresianische Staatsreform », pp. 559, 561 ; Klíma, « Probleme der Proto-Industrie », pp. 176-177 ; Walter, Die österreichische Zentralverwaltung, vol. 2/1/1, pp. 212-214. La proximité de Rudolf Chotek avec François Etienne de Lorraine est soulignée par Donati, "Kaunitz und das Trentino », p. 281 ; sur sa relation étroite avec Kaunitz, voir Uhlî̌r, « Kaunitz und die böhmischen Länder », pp. 490-491.

366 Rogasch, Schlösser und Gärten in Böhmen und Mähren, pp. 214-217.

367 Voir au chapitre IV.1.b.

368 Čelková, « Der Kaiser kommt », pp. 249-253.

369 Il sera quelques années plus tard le président de la Hofkammer ; voir Dickson, Rauscher, « Die Hofkammer im 18. Jahrhundert », p. 854 ; Čelková, « Imperial visits of the Habsburgs », p. 55. 
dans la capitale impériale trois portraits, celui de Marie-Thérèse (P 54), un de François Étienne et un de sa propre personne. Ces portraits sont à l'époque exposés dans la salle de réunion de la Kammerhof de la cité minière ${ }^{370}$.

Grâce à cette visite, la cité de Banská Štiavnica bénéficie de privilèges. Un décret de Marie-Thérèse permet d'établir en 1762 l'Académie des Mines de la ville. Treize ans après la première visite de François Étienne en 1751, les archiducs Joseph et Léopold ainsi que leur beau-frère Albert de Saxe-Teschen, époux de l'archiduchesse Marie-Christine, visitent de nouveau les villes minières du 21 au 31 juin 1764 afin de célébrer la création de l'Académie des Mines qui a eu lieu deux ans plus tôt. Enfin, en 1777, le dernier fils de Marie-Thérèse, l'archiduc Maximilien, vient à son tour à Banská Štiavnica. Rappelons que l'ensemble du royaume de Hongrie est dépendant des états hongrois tandis que ces villes minières représentent une enclave directement liée à Vienne, en plein milieu d'une terre hongroise. La présence impériale y est symbolisée par la commande de portraits.

Les visites et les portraits qui en résultent, représentent un lien direct et personnel des pays, et en particulier des élites, avec la souveraine. En l'occurrence, ils peuvent être un moyen de contourner et d'influencer l'autorité exercée traditionnellement par les diètes: remarquons que les voyages ont surtout lieu à l'occasion des diètes. En Hongrie, les voyages royaux prennent souvent un sens politique et symbolique très fort afin de s'adresser directement à quelques membres de la haute noblesse. La stratégie de la cour tend à renforcer les contacts personnels de la souveraine avec les nobles. Il importe à la souveraine de visiter régulièrement ses sujets, en particulier les personnes qu'elle a placées elle-même à de hautes fonctions ou qui ont fait preuve d'une grande fidélité à son égard au cours de son règne. Lors des diètes hongroises de 1751 et de 1764 , où la question de l'augmentation des impôts se pose, Marie-Thérèse rend visite, de manière ostentatoire, à certains membres de la haute noblesse de Hongrie, au premier rang desquels figure Grassalkovich ${ }^{371}$.

Chacune des visites de Marie-Thérèse est aussi l'occasion pour les élites de se mettre en scène face à la Monarchie et de se montrer comme de fidèles serviteurs de la Maison d'Autriche et de sa représentante, Marie-Thérèse, tout en res-

370 Les tableaux sont aujourd'hui dans la galerie de peintures Josef Kollár à Banská Štiavnica, dans la cinquième salle d'exposition consacrée aux visites impériales des Habsbourg de 1751 et 1764, voir aussi Čelková, « Imperial visits of the Habsburgs » p. 55 ; Čelková, « Die Bergbaukunst », p. 46.

371 Varga, Grassalkovich-Kastély Gödöllo, pp. 52-57 ; concernant la visite de la Marie-Thérèse, voir pp. 58-61 et pp. 27-28 concernant la chambre de Marie-Thérèse lors de sa visite en 1751. 
tant proches de la couronne de Saint Étienne. Les portraits de la souveraine s'insèrent ainsi dans des liens de clientélisme et de familiarité.

Il est couramment admis que le souverain doit séjourner au milieu de son royaume. De telles rencontres contribuent à la réalisation des objectifs politiques de la souveraine au sein du royaume de Saint Étienne. Débutant au début des années 1740, continuant dans les années 1750, ces visites de Marie-Thérèse deviennent une habitude durant les années 1760 et 1770 , lors de la période d'affermissement de la souveraineté de Marie-Thérèse marquée par des réformes. Les nombreux portraits de Marie-Thérèse, en veuve, souvent très simples, à micorps et sans grande ostentation, de l'ancienne Hongrie royale, tout comme les portraits répertoriés par le Musée Červený Kameň, et issus des divers châteaux de la noblesse hongroise, peuvent en témoigner.

Les portraits témoignent de la démultiplication du corps de Marie-Thérèse en une période de crise dynastique et politique. Le don d'ubiquité attribué au portrait prend toute son ampleur et son efficacité. Les visites, puis l'apparition de portraits de Marie-Thérèse, créent l'impression que cette dernière est toujours présente. Selon l'avis d'un théoricien du portrait comme Louis Marin, l'un des objectifs principaux du portrait est de rendre légitime mais aussi présent symboliquement le souverain là où il ne peut se rendre, et là où il s'est rendu mais où il n'est plus, pouvons-nous rajouter ${ }^{372}$.

Le portrait prolonge et perpétue symboliquement la présence de la souveraine. Durant un bref moment, celle-ci devient une présence réelle et corporelle. Employons aussi les mots de commémoration et de reconnaissance comme semblent l'évoquer les dons d'hospitalité. Ces dons permettent de commémorer la présence de la souveraine et de rappeler ainsi le lien unissant Marie-Thérèse et ses élites.

\section{a. Commandes des autorités, notamment urbaines, évènements politiques, et attentes réciproques}

Si la commande de portraits par Marie-Thérèse et ses sujets a lieu tout particulièrement lors de rencontres réelles entre la souveraine et ses élites, lors d'un échange, les portraits royaux peuvent aussi être commandés par les représentants des différents états et ordres lors de diverses occasions comme les couronnements ou lors de la reprise de souveraineté des Habsbourg sur leurs territoires.

372 Marin, Portrait du roi, pp. 9-10. 
Nous souhaitons en effet analyser les commandes de portraits par les autorités urbaines de différentes collectivités territoriales, les magistrats des villes étant notamment d'actifs commanditaires de tableaux.

Les villes se montrent toujours plus indépendantes et plus fortes par rapport à la noblesse. Il est clair que leur poids augmente, notamment vis-à-vis de la noblesse terrienne, mais cela s'applique beaucoup plus à certaines provinces qu'à d'autres. Toutefois, sous Marie-Thérèse déjà, le pouvoir royal commence à empiéter fortement sur leur autonomie. Pourquoi alors une ville commande-telle un portrait de Marie-Thérèse ? Certes, c'est un acte habituel, notamment lors de l'avènement ou de la prise de pouvoir d'un nouveau souverain, comme l'atteste l'exemple de Presbourg en 1742 ou de Bruxelles en 1750. Ces commandes relèvent certainement d'une stratégie d'auto-représentation par rapport aux nobles qui commandent eux-mêmes des portraits de Marie-Thérèse, mais aussi d'une tradition de représentation du souverain. Par leurs commandes de portraits royaux, il est fort à parier que les villes se mettent en scène vis-à-vis de la souveraine dont elles attendent, en échange de ce signe de fidélité et de loyauté, un certain nombre d'avantages ${ }^{373}$.

Vienne est au XVIII ${ }^{\mathrm{e}}$ siècle une ville particulièrement peuplée avec 175000 habitants aux environs de 1750. Les villes de Graz, Linz, Innsbruck et Klagenfurt n'en dénombrent respectivement que 20 000, 10 000, 8500 et $7000^{374}$. Comme les autres villes et les autres états de Basse-Autriche, Vienne est fidèle aux Habsbourg. Son hôtel de ville reçoit un portrait grandiose de Marie-Thérèse surplombé par un médaillon de l'archiduc Joseph en habit de Hussard hongrois, réalisé par Martin van Meytens vers 1744 (P 12) ${ }^{375}$. Les comptes conservés montrent que Meytens a reçu cent ducats de Kremnitz pour le tableau et une médaille pour y avoir ajouté l'image du prince héritier. Le cadre est réalisé par un certain Theobald Trebezksi pour le prix de cent florins ${ }^{376}$.

373 Voir sur ce point les propos intéressants de Paradis, Roy, « Le cueur craintif », p. 109, il est question dans cet article des entrées royales ; selon les auteurs, la somptuosité des réceptions organisées par les villes était une manière « de se faire voir et de se faire entendre du roi dont elles dépendent pour leurs privilèges et leurs libertés ».

374 Klein, « Die Bevölkerung Österreichs », p. 106.

375 Ce tableau fut transféré en 1919 de l'ancien hôtel de ville au musée municipal. Voir Lindinger, « Martin van Meytens »; Lisholm, Martin van Meytens, pp. 57, 59, 99 ; Waissenberger, Schausammlung, pp. 175-176 ; et encore Matsche, " Maria Theresias Bild », p. 213 ; Polleross, " Macht und Image », pp. 65, 67-68; Linsboth, " Herrscherrepräsentation in Rathäusern », pp. 217-218.

376 Weiss, Festschrift aus Anlaß der Vollendung, p. 20. 
Différents portraits de monarques autrichiens ornent déjà les murs de l'ancien hôtel de ville depuis la fin des années $1400^{377}$. Ainsi une image peinte de l'empereur Frédéric III est attestée pour 1471, et une série continue des souverains depuis Charles V se trouve dans les deux salles du petit et du grand conseil de la ville. Des portraits de quelques impératrices sont présents aussi, comme ceux d'Éléonore, la veuve de Ferdinand III, et de l'épouse de Joseph $\mathrm{I}^{\mathrm{er}}$, Wilhelmine Amélie. Selon Karl Uhlirz, le portrait de Marie-Thérèse entraîne cependant un nouvel aménagement de l'hôtel de ville ${ }^{378}$.

Cette commande d'un portrait et ces choix iconographiques ${ }^{379}$, de la part de la ville de Vienne en 1744, en pleine guerre de Succession d'Autriche, peuvent être interprétés comme un signe de ralliement à Marie-Thérèse et à la prétention de la nouvelle dynastie autrichienne à la reconquête de la dignité impériale. Vienne n'est cependant pas la seule ville de Basse-Autriche, ni de la Monarchie, à se doter d'un portrait impérial, et surtout ce portrait n'est pas le seul à Vienne. Un portrait de Marie-Thérèse en robe de dentelle rose, probablement peint vers 1750 par Meytens, figure aujourd'hui au Musée historique de la ville de Vienne $(\mathrm{P} 126)^{380}$. Détail intéressant, un portrait très similaire provient de la guilde des bouchers de la ville de Prague (P 127, Figure 26), ce qui signifie que le portrait de Prague a probablement été commandé et réalisé pour un public local de la ville après 1750, mais que les commanditaires avaient certainement déjà eu connaissance du portrait viennois ${ }^{381}$.

Autre ville de Basse-Autriche, Baden : Le Rollettmuseum de la ville de Baden possède aujourd'hui deux portraits, en pendant, de l'empereur François $\mathrm{I}^{\text {er }}$ et de Marie-Thérèse (P 109, Figure 20), destinés à l'origine à la salle de réception de l'hôtel de ville. C'est en 1744 que le Stadtrichter et le conseil de la ville de Baden décident d'acquérir un portrait de la souveraine ${ }^{382}$, au même moment que Vienne.

377 Weiss, Festschrift aus Anlaß der Vollendung, pp. 19-20.

378 Uhlirz, «Zur Geschichte des alten Wiener Rathhauses », p. 39.

379 Sur ce portrait, voir aussi les chapitres VIII et IX.

380 Ce portrait LG 19 proviendrait de la collection du docteur Auguste Heymann ; voir Baum, Katalog des Österreichischen Barockmuseums, vol. 2, p. 430.

381 Merci à Zuzana Strnadová et à Kateřina Krylová du Musée de la ville de Prague, comme au Musée de la ville de Prague dans son ensemble, pour les informations fournies.

382 Ratsprotokoll 1743-1747, fo . 68r. C'est de là probablement que date l'acquisition des deux magnifiques portraits de Meytens. Au cours du XX $X^{\mathrm{e}}$ siècle, le portrait de François Étienne arriva le premier au Rollettmuseum tandis que le portrait de Marie-Thérèse resta exposé jusque dans les années 1970 dans la salle de l'hôtel de ville. Voir Raths Protocoll de Anno 1743 jusqu' en 1747, fo. 68. Merci au docteur Rudolf Maurer et à Birgit Doblhoff du RollettmuseumStadtarchiv de Baden qui ont coopéré à notre recherche. 
Durant cette époque, les portraits de Marie-Thérèse commandés par les villes de Basse-Autriche peuvent être interprétés comme une façon pour les municipalités de se concilier les bonnes grâces de l'autorité monarchique. On peut aussi supposer que parmi ces municipalités, certaines avaient des contacts avec le centre viennois. De moins en moins représentées à la diète, les villes sont dans une position particulière, toujours plus dépendantes du souverain ${ }^{383}$.

Bien que le royaume de Hongrie ne soit certainement pas le pays de la Monarchie qui dispose de la plus haute densité urbaine, plusieurs villes hongroises possèdent également des portraits de Marie-Thérèse. La capitale de la Hongrie royale, Presbourg, commande dès 1742 auprès du peintre Daniel Schmidelli un tableau représentant Marie-Thérèse en roi de Hongrie pour la salle de conseil de l'hôtel de ville (P 24, Figure 5) ${ }^{384}$. Ce portrait majestueux, de très grand format, est encore à la fin du XIX ${ }^{\mathrm{e}}$ siècle dans l'hôtel de ville démoli en 1903. En 1919, il est transféré dans la galerie de la ville qui s'appuie sur les collections du musée municipal. Il se trouve aujourd'hui dans le palais primatial. En bas du portrait est inscrite la date de réalisation « Ano 1742, Die 31 December ». Un sculpteur de Presbourg du nom de Ludwig Gode exécute les parties sculptées pour le cadre en 1742, il reçoit pour cela vingt florins ${ }^{385}$. Schmidelli est quant à lui rémunéré cent quatre-vingts florins par le magistrat de la ville pour ce portrait ${ }^{386}$. Les autorités de la ville dépensent donc une somme conséquente pour représenter avec faste le nouveau « roi » de Hongrie, Marie-Thérèse, durant une période particulièrement critique.

L'occasion de la commande est bien sûr la commémoration du couronnement de Marie-Thérèse comme roi de Hongrie qui s'est déroulé à Presbourg l'année précédente. Ce couronnement, essentiel aussi bien pour Marie-Thérèse et pour le maintien de la Monarchie que pour la ville, s'est tenu avec magnificence. L'arrivée de Marie-Thérèse à Presbourg le 20 juin 1741 suscite beaucoup d'enthousiasme car tant la noblesse que la ville mettent de grands espoirs dans le nouveau monarque. Le jour même du couronnement, le 25 juin, la bourgeoisie de la ville s'est réunie près de la cathédrale pour saluer la souveraine au cri de Vivat Maria Theresia ${ }^{387}$.

Rappelons que le début du règne de Marie-Thérèse est marqué par la guerre de Succession d'Autriche. Les subsides financiers exigés des Hongrois augmentent considérablement afin de soutenir l'effort de guerre de la jeune souveraine.

383 Pühringer, “'Mitleiden' ohne Mitsprache », p. 107.

384 Merci à Lucia Kuklová de la Galéria mesta Bratislavy au Mirbachov palác de Bratislava.

385 Fidler, « Beiträge », Ars 2-3/1995, partie II, p. 211.

386 Fidler, « Beiträge », Ars 1-3/1997, partie IV, p. 236.

387 Holčík, Korunovačné slávnosti, pp. 36-37. 
Ces derniers acceptent cet effort en promesse de certaines contreparties en matière de privilèges. Cette commande ne serait donc en aucun cas un acte de soumission ou d'adhésion absolue envers Marie-Thérèse. Il s'agit plutôt d'un acte d'adhésion réfléchi et rempli d'attentes. La reconnaissance et le soutien des Hongrois sont décisifs pour Marie-Thérèse en cette période de crise pour la monarchie, alors que plusieurs provinces lui font défaut ou sont occupées par divers ennemis, en premier lieu la Bohême. Ce tableau officialise ainsi dès le début du règne une relation préférentielle du royaume de Hongrie avec la nouvelle souveraine, ce qui contraste avec les rapports souvent tendus de ses prédécesseurs avec les Hongrois ${ }^{388}$.

D’autres portraits de Marie-Thérèse sont commandés peu après le couronnement de 1741 par d'autres villes libres royales hongroises, comme Buda. Évoquons aussi le cas de la ville royale de Sopron et du portrait en pied de Marie-Thérèse en robe de couronnement hongrois, aujourd'hui au château de Fertőd (P 69, Figure 6). Ce portrait a été commandé par le maire Léopold Artner pour la salle de conseil de l'hôtel de ville de Sopron, autrefois Ödenburg, auprès du peintre viennois Johann Baptist Glunck en $1753^{389}$.

Dans les années 1770, période sans convocation de diète puisque la dernière a lieu en 1764, de nouvelles commandes de portraits sont effectuées par les hôtels de ville hongrois tandis que Marie-Thérèse continue d'offrir son portrait. Rajoutons également les portraits de la souveraine et de Joseph II commandés par Presbourg auprès du peintre Joseph Hauzinger dans les années 1760-1770, aujourd'hui conservés dans les réserves de la Galerie nationale de la ville de Bratislava (P 225) ${ }^{390}$. En 1775, c'est au tour de l'hôtel de ville de Komárno (Komárom), ville libre royale hongroise depuis 1745 grâce à Marie-Thérèse, de commander un portrait de Marie-Thérèse en veuve (aujourd'hui au Musée de Bojnice) afin de compléter et de renouveler ses galeries de portraits (P 222) ${ }^{391}$.

La commande de portrait est une manière ostentatoire de choisir et de reconnaître le couple impérial comme une entité dominante, façon aussi d'être associée à la direction des affaires durant une période où le pouvoir monar-

388 La révolte de Ferenc Rákóczi contre Joseph I ${ }^{\mathrm{er}}$ trente ans auparavant était toujours bien présente dans les mémoires ; sur ces évènements, voir Bérenger, La Hongrie des Habsbourg, vol. 1, pp. 183-204 ; Csáky, « Die Einordnung Ungarns », pp. 151-155 ; Ducreux, « La monarchie des Habsbourg », pp. 359-360 ; Várkonyi, « Der König und der Fürst » ; Vocelka, Glanz und Untergang, pp. 87-88.

389 Serfőző, « Repräsentation Maria Theresias in Ungarn », p. 314. Ce tableau se trouve depuis les années 1960 dans le palais Esterházy à Fertőd.

390 Papco, Rakúsky barok, vol. 2, p. 516.

391 Papco, Österreichisches Barock und die Slowakei, p. 444. 
chique tend à vouloir centraliser l'autorité entre ses mains au détriment parfois des villes.

Les commandes des élites, notamment des villes, et les évènements politiques sont ainsi indéniablement liés, mais les portraits sont aussi à mettre sur le compte d'une reprise en main étatique.

\section{b. Commandes de portraits, reprise en main étatique, et attentes des élites}

Dans la capitale bruxelloise comme dans l'ensemble des Pays-Bas autrichiens, il est possible d'analyser les portraits royaux comme des signes de la popularité de Marie-Thérèse, une célébration de la part des élites après avoir retrouvé l'autorité d'une monarchie des Habsbourg jugée plus conciliante que les autres régimes subis, en l'occurrence celui de la France ${ }^{392}$. Marie-Thérèse est également intéressée par ces riches provinces. Parce qu'ils sont les centres traditionnels du pouvoir dans la province des Pays-Bas autrichiens, les hôtels de ville sont d'actifs commanditaires de portraits de Marie-Thérèse dans un contexte de guerre, de reconquête autrichienne, de légitimation et de rivalité entre villes. Les Pays-Bas sont progressivement intégrés dans le système administratif centralisé de la Monarchie ${ }^{393}$. Des portraits de Marie-Thérèse sont ainsi conservés dans l'ancienne province des Pays-Bas autrichiens, et dans les lieux de voyage du gouverneur Charles de Lorraine au sein de ces provinces, tant à Bruxelles qu'à Gand, Bruges et Ostende ${ }^{394}$.

Marie-Thérèse ne visite pas tous ses pays avec la même régularité. Si la souveraine et son époux parcourent les pays héréditaires moraves, tchèques, autrichiens et hongrois à l'occasion des couronnements, Marie-Thérèse ne franchit jamais la frontière des Pays-Bas autrichiens par exemple. Mais si cette province ne reçoit aucune visite de Marie-Thérèse en personne, sa tante Marie-Élisabeth de Habsbourg (1680-1741, gouvernante des Pays-Bas entre 1725 et 1741) dans un premier temps, puis son beau-frère Charles de Lorraine (1712-1780, gouverneur des Pays-Bas autrichiens entre 1741 et 1780), résident à Bruxelles. Ils parcourent à maintes reprises les provinces, à la manière de véritables souverains. En son absence, la présence de Marie-Thérèse est remplacée par un portrait, en plus de ses représentants.

392 Notons qu'une décennie après la mort de Marie-Thérèse, ces provinces seront en pleine révolte contre la dynastie.

393 Galand, « Kaunitz et les Pays-Bas autrichiens ».

394 Sur les voyages du gouverneur général, voir Galand, Charles de Lorraine, pp. 30-33. 
Dès son arrivée aux Pays-Bas en 1749, Charles de Lorraine se rend en Flandre pour célébrer le retour de cette province sous la domination des Habsbourg après la phase d'occupation française ${ }^{395}$. Durant les années d'occupation, les Français ont peu à peu acquis une mauvaise réputation. Les Bruxellois leur reprochent des réquisitions multiples et un manque de respect pour leurs usages et libertés ${ }^{396}$. Après 1749 , les témoignages de fidélité des habitants des PaysBas à l'égard de la souveraine sont très étroitement liées à la popularité de son beau-frère ${ }^{397}$. Il est donc parfaitement concevable que l'hôtel de ville de Bruxelles commande un portrait équestre de Marie-Thérèse, portrait représentant la souveraine de manière triomphante, avec des puttis et leurs trompettes pour annoncer l'arrivée de Marie-Thérèse ${ }^{398}$. L'hôtel de ville de Bruxelles possède en effet deux tableaux de la souveraine, l'un de Hieronymus Doffy (P 83, Figure 9), l'autre de Jean-Baptiste Millé (P 84, Figure 36) ${ }^{399}$. Le portrait de Marie-Thérèse à cheval par Millé est probablement commandé vers $1750^{400}$, après la reconquête des Pays-Bas autrichiens par la dynastie autrichienne. La commande d'un portrait de la souveraine avec en arrière-plan la représentation de la ville bruxelloise, l'église Sainte Gudule notamment, peut être considérée comme un hommage de la ville à l'occasion du retour de Bruxelles dans le giron autrichien ${ }^{401}$. Ce portrait doit être replacé dans son contexte, celui de l'invasion des Pays-Bas autrichiens en 1744 et leur libération quelques années plus tard. La souveraine représentée triomphante rappelle ainsi que le 21 février $1746^{402}$, les Français prennent la ville de Bruxelles avant qu'elle ne soit reconquise par les troupes autrichiennes en $1749^{403}$. Les garnisons françaises quittent en effet la ville de Bruxelles le 28 janvier $1749^{404}$. $\mathrm{Au}$ début du printemps arrive le général marquis de Botta-Adorno, nommé minis-

395 Galand, Charles de Lorraine, pp. 30-31. L'auteur insiste sur le fait que les défaites essuyées par le prince sont oubliées ainsi que l'occupation française prolongée par ces défaites. Henne, Wauters, Histoire de la ville de Bruxelles, tome 2, pp. 272-273.

396 Henne, Wauters, Histoire de la ville de Bruxelles, tome 2, pp. 272-273.

397 Galand, Charles de Lorraine, p. 31.

398 Nous reviendrons plus précisément sur ce portrait dans le chapitre IX.5.

399 Les informations qui suivent ont été recueillies auprès du Musée de la Ville de Bruxelles et de la Maison du Roi. Merci à Bérengère de Laveleye, assistante scientifique.

400 Merci à Bérengère de Laveleye pour ces informations.

401 Sur la rentrée des forces autrichiennes à Bruxelles, voir Browning, The War of the Austrian Succession, pp. 362-363 ; Duchesne, "Le souvenir », p. 180 ; Verniers, Un millénaire d'histoire de Bruxelles, pp. 378-379.

402 Henne, Wauters, Histoire de la ville de Bruxelles, tome 2, p. 267.

403 Ce tableau équestre est toujours exposé sur le mur du fond au premier étage de l'hôtel de ville de Bruxelles, dans la même salle que le portrait de Marie-Thérèse réalisé par Hieronymus Doffy.

404 Henne, Wauters, Histoire de la ville de Bruxelles, tome 2, p. 276. 
tre plénipotentiaire pour remplacer Kaunitz ${ }^{405}$, suivi du duc Charles de Lorraine quelques semaines plus tard.

Les portraits soulignent la légitimité de la Maison d'Autriche, et en particulier celle de sa souveraine Marie-Thérèse. Les Pays-Bas sont en effet une région stratégique pour la Monarchie, très avantageuse d'un point de vue économique. Les états de Brabant, qui siègent à Bruxelles, gagnent de plus en plus de prestige. Bruxelles, qui n’a été jusqu'alors qu'une capitale administrative, devient le centre de la vie politique et culturelle du pays. C'est aussi une démonstration de force des états de Bruxelles qui, de leur plein gré, rendent hommage à la Monarchie et à Marie-Thérèse après des années difficiles d'occupation française. Ces états entendent cependant bien conserver leur autonomie et être reconnus comme une entité consciente d'elle-même.

Par la suite, Kaunitz considère que ces provinces opulentes, bien qu'éloignées, peuvent et doivent mieux participer aux efforts de l'ensemble des possessions Habsbourg ${ }^{406}$. Cette volonté devient même un impératif avec la guerre de Sept Ans et la perte de la Silésie. La Monarchie s'est en effet endettée auprès de ses pays. Les commandes de portraits de Marie-Thérèse par les autorités locales, tout comme l'envoi de portraits notamment sous forme de dons, sont autant de manières de resserrer le lien entre les élites et le pouvoir autrichien. Les deux formes de transfert, le don de portraits par Marie-Thérèse et la commande des élites elles-mêmes, comme c'est le cas aux Pays-Bas avec le don princier à la ville de Gand et la commande de la ville de Bruges et de Bruxelles, renvoient à un processus concurrent et similaire. Qui va devancer l'autre dans l'envoi et la commande de portrait ? Ces deux formes de transfert, tout en rivalisant entre elles, se complètent autour de l'image de Marie-Thérèse.

Célébrer la reconquête sur les Français a dans tous les cas lieu à l'initiative des élites elles-mêmes. Les Habsbourg-Lorraine sont en effet de nouveau l'entité dominante. Autre grande cité flamande, à l'occasion quelque peu rivale de Gand et de Bruxelles, Bruges conserve dans son hôtel de ville deux portraits de Marie-Thérèse, commandés par les autorités de la ville. L'un des portraits est une copie d'un portrait réalisé par Martin van Meytens et exposé originellement à l'hôtel de ville de Gand (P 122). L'original est toujours à sa place initiale tandis que sa copie, réalisée par le peintre brugeois Matthias de Visch, se trouve à l'hôtel de ville de Bruges (P 123, Figure 10). Le second portrait recensé dans les collections urbaines brugeoises a également été réalisé par Matthias de Visch en

405 Henne, Wauters, Histoire de la ville de Bruxelles, tome 2, p. 277.

406 Galand, « Kaunitz et les Pays-Bas autrichiens », pp. 220-221 ; Zedinger, " Kaunitz und Johann Karl Cobenzl », p. 209. 
octobre 1749 après que les Pays-Bas autrichiens sont repassés sous le contrôle des Habsbourg (P 124, Figure 11).

Posséder le même portrait que Gand, qui a reçu le portrait comme don de la souveraine, peut être interprété comme une marque d'auto-représentation de la ville manufacturière de Bruges, tant par rapport à la cité voisine que par rapport à Vienne. Le secteur de la dentelle est fragilisé au XVIII ${ }^{\mathrm{e}}$ siècle, aussi la concurrence entre villes brabançonnes est-elle importante $e^{407}$. Cette stratégie sociale d'acteurs politiques et économiques manifeste une forme de reconnaissance vis-à-vis de la Monarchie et se double d'une volonté d'imitation et d'émulation entre les villes d'un même territoire pour avoir une copie, la plus ressemblante possible, de la version originale offerte par Vienne. C'est à qui obtiendra le plus beau portrait de Marie-Thérèse et se montrera surtout avec ce tableau. Dans ce cas précis, la ville de Bruges se hisse au rang de Gand, mue probablement par une stratégie de rivalité et de concurrence vis-à-vis de la cité gantoise qui se cristallise autour de la commande de tableaux royaux. Bruges se représente à un moment précis du règne, lors de la libération des Pays-Bas par les troupes autrichiennes, avec le portrait de Marie-Thérèse inspiré d'un modèle viennois de cour très diffusé alors.

Généralement, les portraits font partie de la représentation traditionnelle du pouvoir en des lieux qui incarnent l'autorité comme la Maison des états ou encore les hôtels de ville. Le portrait de Lier ( $\mathrm{P}$ 82), représentant Marie-Thérèse avec ses couronnes, est assez semblable à celui réalisé par le peintre Doffy suspendu dans l'hôtel de ville bruxellois (P 83, Figure 9). Le conseil urbain de Lier ${ }^{408}$ commande ainsi un portrait de Marie-Thérèse en 1745, peu après la reconstruction et l'agrandissement de l'hôtel de ville (P 82 $)^{409}$. Selon les reproductions aujourd'hui disponibles, le portrait de Lier était exposé au centre, en plein milieu de la salle, à côté des armoiries, des blasons héraldiques et des drapeaux de la cité.

Dans les années 1745, après les couronnements de Marie-Thérèse en roi de Hongrie et de Bohême, une partie des Pays-Bas autrichiens est encore sous domination étrangère mais François Étienne est enfin couronné empereur à Francfort. Les Habsbourg retrouvent alors une certaine forme de reconnaissance, de prestige et de légitimité. Ce n'est pas seulement à Vienne que le besoin de por-

407 Merci tout particulièrement à Klaas van Gelder d'avoir attiré notre attention sur ce point. 408 Lier (ou Lierre) se trouve entre Bruxelles et Anvers, relativement au nord des Pays-Bas autrichiens.

409 Je remercie Luc Coenen, conservateur du Musée de Lier qui m’a communiqué ces renseignements; voir aussi Lens, Mortelmans, Gids voor oud Lier, p. 19. Voir chapitre III. 
traits royaux se fait sentir, mais aussi et surtout, dans les différents royaumes et territoires, en particulier ceux qui sont éloignés du centre viennois.

Dans une situation politique difficile où il s'agit de raffermir la légitimité de la souveraine et de sa dynastie, le portrait royal se doit d'être multiplié. L'exemple de la communauté urbaine et marchande de Bolzano au sud de la Monarchie paraît intéressant dans la mesure où la cité commande des portraits de Marie-Thérèse à deux reprises, au moment même où elle espère la visite et la générosité impériales.

Dans le passé, un statut remontant à l'époque de l'archiduchesse du Tyrol, Claudia de Médicis, s'est avéré déterminant pour la reconnaissance de la ville comme centre commercial de première importance dans la région. Mais au XVIII ${ }^{\mathrm{e}}$ siècle la situation évolue, se détériore parfois, et la ville de Bolzano n'est plus le centre brillant des foires d'antan. La ville est soumise aux initiatives et réformes de plus en plus centralisatrices des Habsbourg. Ses privilèges sont alors progressivement abolis, même si la ville reste importante et se modernise d'un point de vue économique ${ }^{410}$. Toutefois, si les élites marchandes de la ville dépendent de la Monarchie, cette dernière continue encore de dépendre d'elles en matière de soutien financier et politique. La relation est complexe, interdépendante, elle n'est pas exempte de tensions latentes, cachées derrière la commande et l'envoi de portraits.

Deux tableaux, datés de 1743 (P 29, Figure 17) et de 1765 (P 104), sont commandés par les magistrats mercantiles de la ville de Bolzano, cité de neuf mille habitants, consciente de sa position de passage stratégique entre l'Italie et le reste de l'empire. Malgré certaines difficultés, Bolzano est une ville au demeurant encore riche et importante au XVIII ${ }^{\mathrm{e}}$ siècle. Les élites de la ville, en particulier les élites marchandes, ont des attentes vis-à-vis de Marie-Thérèse, surtout en 1743. Mais la nouvelle édition de l'ordonnance mercantile de Bolzano, promulguée le $1^{\mathrm{er}}$ avril 1744 , ne contient pas de grandes modifications ${ }^{411}$. Chaque occasion est utilisée pour témoigner sa loyauté et se rappeler aux membres de la famille impériale de passage. Le premier portrait est commandé à l'occasion du couronnement de Marie-Thérèse comme roi de Bohême, à un moment assez crucial où la souveraine commence à retrouver sa souveraineté sur les territoires, et le second à l'occasion du mariage de l'archiduc Léopold avec l'infante MarieLouise d'Espagne, à Innsbruck en août $1765^{412}$. Ces deux tableaux souhaités

410 Bonoldi, « Wo man Leichtigkeit und Freiheit genutzt hat », pp. 30, 32, 34; Krasensky, Die Bozener Marktordnung, pp. 23-24; Rizzolli, « Bozen », pp. 21-29. Sur le statut octroyé par l'archiduchesse Claudia en 1635, voir Denzel, Die Bozner Messen, pp. 51-59.

411 Rizzolli, « Bozen », pp. 30-31; voir aussi Festi, Nardelli, « Katalog », pp. 118-119.

412 Festi, Nardelli, « Katalog », p. 146-147. Sur le voyage de la cour à Innsbruck, voir Haslinger, « Die Veränderung der Kayserlichen Residentz ». 


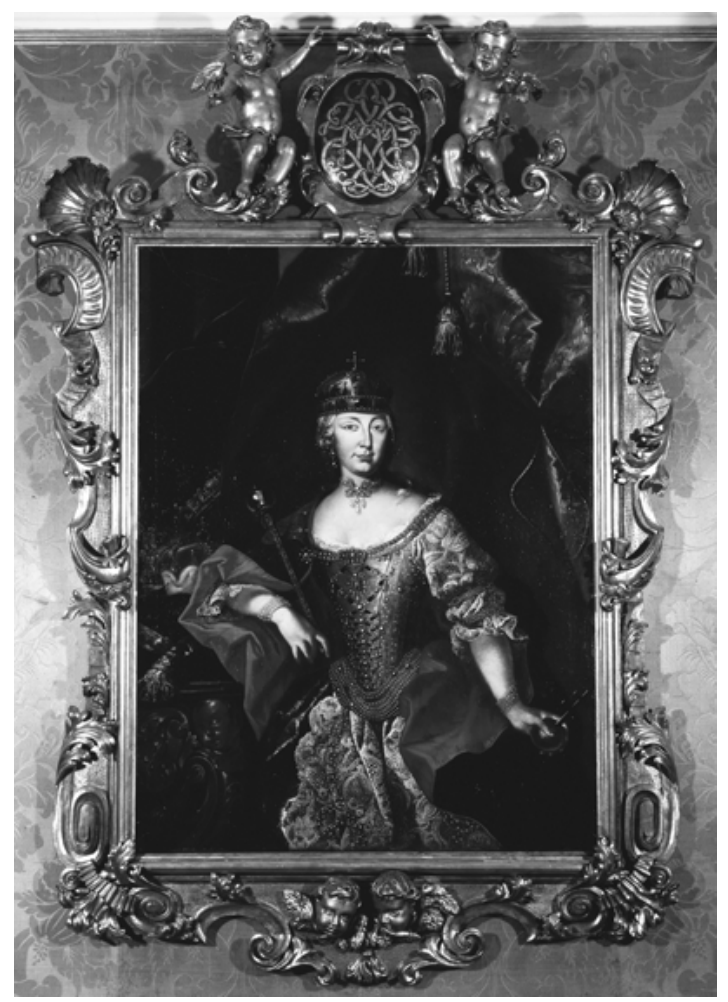

Figure 17: Atelier de Martin van Meytens, Marie-Thérèse en roi de Hongrie, 150 x $112 \mathrm{~cm}, 1743$, commande des autorités mercantiles de Bolzano, Inv. Nr. 304, Merkantilmuseum BozenMuseo Mercantile di Bolzano, Italie.

par les autorités urbaines d'une ville, assez éloignée du centre viennois, mais disposant cependant d'une position stratégique, témoignent de la valeur symbolique, marchande et de négociation que peut revêtir l'image de la souveraine. Pour le premier des portraits commandé en 1743, la dépense de quatre-vingt -sept florins apparaît dans le livre de comptes du magistrat pour la foire de la Fête$\operatorname{Dieu}^{413}$, une des quatre foires annuelles de Bolzano ${ }^{414}$. C'est la ville qui dépense cette somme pour acquérir le portrait, qui est alors exposé dans la salle d'audience des magistrats.

413 Festi, Nardelli, « Katalog », p. 156.

414 Denzel, Die Bozner Messen, p. 58; Krasensky, Die Bozener Marktordnung, p. 22; Rizzolli, « Bozen », p. 17. Merci aussi à Elisabetta Carnielli du Musée Mercantile de Bolzano. 
Il existe un fort échange de services, imprégné d'attentes réciproques, entre Marie-Thérèse et les magistrats de la ville. Le bon fonctionnement des voies de transports est aussi un objectif et une requête importante de la part des commerçants $^{415}$. Le magistrat mercantile accorde même soixante-trois mille florins d'emprunts à Marie-Thérèse en 1763 pour réparer les chemins détruits par des inondations. Malgré l'importance de la cité et l'attente de ses habitants, MarieThérèse ne s'y rend qu'en 1738 lors de son voyage vers Florence (de cette période date probablement l'arrivée du portrait $\mathrm{P} 3^{416}$ ), puis le 11 mai 1739 , très rapidement, lors du trajet de retour vers Vienne. Presque trente ans plus tard, en 1765, la ville de Bolzano attend impatiemment l'arrivée de Marie-Thérèse. Malheureusement la réception, prévue en août 1765, ne peut avoir lieu en raison de la mort soudaine de l'empereur à Innsbruck ${ }^{417}$.

Les portraits reflètent les demandes sociales et politiques des villes, corps important dans la société d'alors, qui tentent de réaffirmer leur position en soulignant leur relation personnelle et leur proximité avec Marie-Thérèse. Il est intéressant de souligner ces exemples où les élites urbaines parviennent à commander et à faire exécuter elles-mêmes des portraits à plusieurs reprises.

Les états provinciaux commandent et exposent eux aussi des portraits de Marie-Thérèse comme l'attestent des exemples de notre corpus, tout particulièrement en Carinthie et en Basse-Autriche. En dehors de ces deux régions, l'hôtel de ville de Luxembourg conserve aujourd'hui un portrait de Marie-Thérèse réalisé par le peintre flamand Jean-Pierre Sauvage vers 1750 (P 34). Le tableau était autrefois exposé dans le palais grand-ducal, ancien hôtel des états ${ }^{418}$.

Le Landesmuseum, le Musée régional de Klagenfurt en Carinthie, possède un portrait de la souveraine, une copie d'après un original de Meytens datant de 1750, qui est réalisée par le peintre viennois Jacob Michel en 1753, pour l'actuelle salle de session de la diète (P 125) ${ }^{419}$. En Carinthie, il est possible de voir là un témoignage supplémentaire de la mainmise progressive du pouvoir central et de la perte d'indépendance et d'autogestion, du moins financière, des états. Pour faire commander et réaliser eux-mêmes un portrait de Marie-Thérèse, certes somptueux, pour leur salle de réception, ils ne peuvent se passer de la permission et de l'aide apportées par le pouvoir central, leur autonomie est donc réduite. Les Landstände, les états provinciaux, commandent le 12 juillet 1753 par

415 Rizzolli, «Bozen », p. 31.

416 Meloni Trkulja, «72. Bildnis der Maria Theresia von Österreich », p. 145.

417 Trapp, Maria Theresia und Tirol, p. 26. Sur le voyage italien de Marie-Thérèse en 1738 et 1739, voir aussi Bressan, « Maestà sovrana », pp. 25-33.

418 May, Marie-Thérèse Duchesse de Luxembourg, p. 9.

419 Sur ce portrait et ce peintre, voir chapitre III. 
l'intermédiaire d'un de leurs agents viennois le portrait « à la gloire publique et perpétuelle, pour la salle de la diète ici, où se tiennent aussi les assises de la trèshaute justice princière ${ }^{420}$.

Les frais s'élèvent au total à plus de deux cent cinquante florins, dont cent florins reviennent au peintre Jacob Michel. La toile et le cadre doré reviennent à peu près à la même somme, tandis que le reste doit permettre de couvrir les frais de livraison. Selon ce qu'en rapporte Wilhelm Deuer ${ }^{421}$, les états ne parviennent cependant pas à payer eux-mêmes la somme. Ils ne réussissent à se procurer l'argent nécessaire qu'en vendant une certaine quantité de poudre de l'arsenal. Une confirmation de l'administration princière de la province, la $R e$ präsentation und Kammer récemment créée, est nécessaire pour accomplir toutes ces transactions. Omettant cette procédure, les états sont soumis à des remontrances. Malgré cela, une partie de la somme de deux cent cinquante florins est finalement payée par la caisse de contribution.

Quant à Vienne, deux portraits de Marie-Thérèse sont commandés successivement pour l'ancienne Maison des états (Landhaus) de Basse-Autriche. Le premier (P 128, Figure 27) apparaît vers 1750, destiné à la salle du conseil (Rathstube), où il remplace probablement une représentation de Charles VI. Après le couronnement de Joseph II comme roi des Romains en 1764, les états font à nouveau peindre pour la salle des chevaliers (Ritterstube) les portraits de Marie-Thérèse (P 153) et de Joseph II. Les deux tableaux peuvent être attribués à l'atelier de Meytens ${ }^{422}$.

Si les états souffrent de problèmes financiers et de perte d'autonomie, ils parviennent souvent, après bien des efforts, à payer le portrait royal qu'ils ont commandé.

D’autres provinces de la Monarchie comme le comté princier de Gorizia (P 118) font aussi état de l'acquisition d'un portrait royal, ou dans ce cas plus précisément d'un cadre, obtenu en partie grâce aux propres moyens de la communauté. Il est intéressant de réfléchir à la signification de la commande d'un cadre destiné à un portrait de Marie-Thérèse par les états provinciaux comme ceux de Gorizia. Par cette commande, la commune témoigne d'une certaine loyauté vis-à-vis des Habsbourg, et plus encore d'une certaine conscience de sa valeur.

420 Deuer, Das Landhaus zu Klagenfurt, p. 70: «pro perpetuo decore publico für 'das alhiesige landtagzimer, alwo aber zugleich das allerhöchste landesfürstliche landrecht gehalten ». 421 Deuer, Das Landhaus zu Klagenfurt, p. 70.

422 Krug, « Denkmäler », pp. 231-235. 
Durant la session du 16 juillet 1749 à Gorizia, il est décidé que le portrait de la souveraine, muni du cadre et des décorations du cadre, seront réalisés et payés avec l'argent d'un certain sieur Codelli et deux caisses de vin du Veneto ${ }^{423}$.

L'auteur de la notice du catalogue de Gorizia de 1981-1982, Coronini Cronberg, rapporte en effet l'arrêté du 16 juillet 1749, il ne dit pas explicitement qui l'a pris, mais il s'agit certainement des états provinciaux. Selon cet arrêté, les dépenses faites pour le portrait de la souveraine et pour son cadre sont à régler avec l'argent donné par le sieur Agostino Codelli que nous venons de citer, avec une autre somme perçue par la confiscation de deux fûts de vin du Veneto qui avaient été importés illicitement.

Deux portraits distincts ont vraisemblablement existé à Gorizia : l'un commandé par les états provinciaux en 1749, et un autre réalisé après 1759, vraisemblablement pour l'archevêque. Les états avaient commandé un cadre destiné au portrait de 1749. En 1982, on exposait ce cadre avec le tableau post-1759. Il s'agit d'un portrait qui appartenait à la « Curia Arcivescovile », c'est-à-dire au palais archiépiscopal. Rien n'est dit sur la provenance de ce tableau. Ce portrait pourrait avoir été destiné au premier archevêque de cet archidiocèse créé en 1751. Le titre de la notice l'attribue à un " peintre anonyme du XVIII ${ }^{\mathrm{e}}$ siècle ». Beaucoup de portraits de Gorizia ont en effet disparu lors de la Guerre de 1914-1918. Le cadre réalisé par un dénommé Lampi était ainsi destiné à un portrait de la souveraine datant de 1749 , qui est désormais perdu ${ }^{424}$.

L'auteur de la notice du catalogue de 1982, Coronini Cronberg ${ }^{425}$, note que le portrait exposé en 1982 est une copie d'après un portrait de Meytens réalisé pour l'Académie de Vienne en 1759, adaptée à un format plus petit. Le portrait était alors inséré dans le riche cadre doré qui était la propriété de l'Administration provinciale de Gorizia. Ce cadre était originalement destiné à « un portrait semblable de représentation de la souveraine dans la salle des réunions des états provinciaux de Gorizia ${ }^{426}$. Une inscription sur le cadre, qui indique la date de 1749, nomme les artisans qui l'ont créé: Antonio Prestinti, « caelator », sculpteur, et Francesco Lampi, « aurator » - c'est-à-dire doreur ${ }^{427}$.

423 Voir Coronini Cronberg, «Anonimo secolo XVIII, Ritratto dell'imperatrice Maria Teresa », p. 40. Au sujet du « patricien » Codelli, « surpris en plein délit » de contrebande, le catalogue n'offre pas de références certaines.

424 Merci à Alessandro Quinzi de Gorizia pour ces informations.

425 Voir Coronini Cronberg, "Anonimo secolo XVIII, Ritratto dell'imperatrice Maria Teresa », p. 40.

426 Coronini Cronberg, « Anonimo secolo XVIII, Ritratto dell'imperatrice Maria Teresa », p. 40.

427 Voir chapitre III. 
Dans le domaine de la commande, ou de la volonté de commander des portraits, de la part des espaces étatiques, mentionnons enfin une lettre du président du Banat, François comte de Vilana-Perlas, marquis de Rialp, au président de la chambre aulique, Königseggs-Erps, en $1756^{428}$. Le président du Banat explique comment il faudrait réaménager le palais civil qui vient d'être inauguré à Temesvár (Timişoara aujourd'hui), de nos jours le Palatul Baroc. En plus des logements de fonction du président, ce palais accueille une partie de l'administration et, surtout, les conseils de l'administration régionale. Fait amusant et significatif, l'auteur constate qu'il lui manque avant tout un portrait de Marie-Thérèse.

Dans sa lettre de recommandation concernant un ingénieur-conducteur, François Perlas en profite pour informer son correspondant des travaux nécessaires dans son logement. Il estime que certains aménagements seraient aussi les bienvenus dans le reste du bâtiment.

[. . .] Ainsi, je n'attends que les ordres de Votre Excellence là-dessus. Je ne scay si elle ordonera que, dans le nouvau bâtiment, l'on y mette les armes de Sa Majeste avec quelques devises, come il conviendroit dans une maison de justice. il faudroit aussi que nous ussions dans la chambre du conseil le portroit de sa majesté [...].

Temesvar, ce 16 août 1756.

Le très humble et très obéis[sant] serviteur, François Comte Perlas Marquis de Rialp ${ }^{429}$

En dehors du fait que cette anecdote témoigne de l'engouement pour le portrait royal, il est intéressant de constater qu'un espace étatique se voit, tout naturellement, décoré d'un portrait de sa souveraine dans la chambre du conseil.

Tandis que les hôtels de ville et les autres institutions étatiques commandent et exposent aussi des portraits royaux, d'autres institutions, comme les académies et les universités, sont encore plus directement soumises à l'autorité centrale viennoise, et très imprégnées par l'image royale. Ces institutions sont au demeurant - du fait de leur existence même - les signes visibles de l'influence grandissante de la puissance étatique en train de se former. Les universités sont également des institutions qui bénéficient d'une certaine indépendance et peuvent éventuellement constituer un contre-pouvoir, même si sous le règne de Marie-Thérèse, elles sont toujours davantage sous l'autorité du pouvoir central.

428 OeStA/FHKA AHK HF Ungarn, VUG, KT 29: « Berichte des Temesvarer Landespräsidenten Graf Perlas an den Hofkammerpräsidenten Graf Karl Königsegg-Erps, meist betreffend die Türkei », lettre $\mathrm{n}^{\circ} 115, \mathrm{f}^{\circ} .500 \mathrm{v}, 16 / 08 / 1756$.

429 Merci à Benjamin Landais de nous avoir communiqué ces archives. Landais, Gouverner le Banat habsbourgeois au milieu du XVIII ${ }^{e}$ siècle, p. 237. 


\section{c. Commandes de la part des universités et des académies lorsqu'une institution a été fondée ou réformée}

Un exemple intéressant et périphérique est l'université de Fribourg-en-Brisgau qui commande elle-même le portrait royal (P 158). Comme nous l'avons déjà évoqué dans le chapitre IV, au sein de l'université de Fribourg ${ }^{430}$, la commande d'un portrait est liée à des réformes profondes de l'institution qui la font passer sous un contrôle étatique plus étroit.

Les autres institutions comme les Académies commandent ou reçoivent, elles aussi, des portraits de Marie-Thérèse. Les Académies sont des espaces de pouvoir et de savoir comme les universités. Relais du pouvoir, elles commandent des portraits royaux pour leurs bâtiments, à moins qu'elles n'en reçoivent de la part de Marie-Thérèse. L'Académie des Beaux-Arts de Vienne commande ainsi en 1759 un portrait de la souveraine. À l'occasion de la nomination de Martin van Meytens comme directeur de l'Académie de Vienne en 1759, un nouveau siège est attribué à l'institution dans le nouveau bâtiment de l'université. Pour la salle de conseil, Franz Anton Maulbertsch réalise une fresque murale, et Martin van Meytens le portrait de Marie-Thérèse. Rappelons l'importance de Maulbertsch, qui a réalisé des fresques dans une grande partie de la Monarchie. Ce portrait de Marie-Thérèse de 1759 est donc une possession de l'Académie viennoise depuis le début, le portrait se trouve « dans un cadre sculpté et tout entièrement recouvert d'or », peut-on lire (P 130 $)^{431}$. Fait particulièrement intéressant, le président de l'Académie de Vienne d'alors, le baron Sperges, commande des portraits de Marie-Thérèse ( $\mathrm{P}$ 227), de François Étienne et de Joseph pour l'Académie de Mantoue. L'Académie viennoise se charge ainsi de l'équipement des académies provinciales ${ }^{432}$.

La Monarchie est en effet en voie de consolidation. Dans les espaces du savoir, le portrait de la souveraine la fait apparaître comme protectrice des œuvres d'art, des industries, des talents et des cultures. L'université et les académies permettent de former les futurs fonctionnaires d'État qui travaillent et servent la Monarchie. L'éducation est en effet un aspect fondamental de la mise en place de l'État moderne.

430 Revoir le chapitre IV.

431 Weinkopf, Beschreibung, p. 81.

432 Sattler, Lebensgeschichte des Hubert Maurer, p. 47. 


\section{Conclusion}

Le portrait s'insère dans un mode de gouvernement qui manifeste tant l'affection et la reconnaissance de la souveraine pour ses sujets que l'affection et la loyauté, plus ou moins intéressées, des sujets pour leur suzeraine. Marie-Thérèse commande des portraits afin de les envoyer vers les résidences impériales. Certains portraits sont aussi un moyen de récompense et de remerciement, en particulier lorsqu'ils sont commandés par Marie-Thérèse pour être offerts à d'autres. Ce sont surtout des outils de communication et de légitimation, adressés en particulier aux acteurs politiques et sociaux, également intéressés au fonctionnement du pouvoir.

La commande de portrait apparaît notamment aux grands moments de la vie et du règne de Marie-Thérèse, les deux dimensions étant liées : les couronnements, la convocation d'assemblées comme les diètes, la naissance de Joseph II, l'héritier du trône, les mariages, la mort de François Étienne. Ces évènements participent ensemble à la volonté de diffuser à certains moments précis l'image de Marie-Thérèse par le biais d'images royales. Faisant suite à la visite de la souveraine lors de grandes occasions, comme les couronnements et les diètes, la commande et l'envoi de portraits resserrent les liens entre MarieThérèse et les grands des royaumes.

Si les commandes de la cour forment près de la moitié des tableaux du corpus, l'autre moitié des portraits est commandée par les élites après une visite de Marie-Thérèse et durant certains moments stratégiques et cruciaux du règne. Les commandes des élites et de la cour répondent dans l'ensemble à des procédures similaires, à des occasions et à des moments semblables, avec des portraits commandés ou offerts à la suite de visites impériales. Un cas particulier d'occasion de commande peut en combiner plusieurs, une visite et un couronnement se combinent par exemple souvent.

Marie-Thérèse voyage et visite ses sujets, l'occasion pour elle d'offrir des portraits, comme pour les élites l'occasion de commander des portraits royaux. L'activité de voyager est liée à la structure et au fonctionnement de la Monarchie mais aussi à la situation du règne de Marie-Thérèse. Il s'agit de réaffirmer la légitimité de la souveraine et de la Maison d'Autriche durant une période de crise. Dans ce contexte, gouverner nécessite l'exécution d'un certain nombre de rituels monarchiques. Les dons d'hospitalité à la suite de voyages sont une manière courante de faire circuler les portraits royaux. Aux dons de Marie-Thérèse répondent les commandes des élites de la Monarchie, presque aussi nombreuses que les dons royaux, et parfois même plus somptueuses. Ces commandes participent très activement au processus de diffusion du portrait royal, que les portraits soient commandés à l'issue ou dans l'attente d'une visite royale et impériale. Une forme de réciprocité s'instaure dans les attentes des uns et des autres. 
La rencontre entre Marie-Thérèse et ses interlocuteurs prend son sens le plus profond en se concrétisant lors d'un échange réel matérialisé par une scène d'hospitalité et de réception, honorant ceux qui reçoivent et ceux qui sont reçus, suivie par l'apparition consécutive du portrait de Marie-Thérèse.

La souveraine " reconquiert », par sa présence picturale et visuelle, ses territoires, les uns après les autres, elle les parcourt, rend visite aux instances importantes. Les commandes de portraits interviennent ensuite. Les tableaux prennent alors une valeur de négociation qui engage les deux interlocuteurs, autant celui qui expose le portrait, que celui qui le commande, qui peut être le même. Le don de portraits resserre et renforce les liens avec des personnes d'importance mais aussi avec des communautés urbaines et ecclésiastiques. La commande des portraits de la part des futurs possesseurs apparaît comme un gage de loyauté, ou du moins une volonté de représenter cette loyauté, empreint d'attentes vis-à-vis du pouvoir central.

Grâce au portrait, des relations de clientélismes ainsi que les rapports amicaux unissant Marie-Thérèse à certains nobles et certains hauts dignitaires, sont rendus plus étroits et tangibles. La Monarchie se construit dans un rapport de réciprocité. La commande et l'exposition de portraits relèvent alors d'un acte commun de reconnaissance. Lorsqu'elle offre son portrait, Marie-Thérèse reconnaît ses élites, leur importance et leur valeur. Réciproquement, lorsqu'elles commandent des portraits ou reçoivent et exposent l'image royale, les élites reconnaissent, à un moment donné, la valeur et la position de leur souveraine. Ils la perçoivent comme « leur » souveraine. Ce comportement n'est pas exempt d'espérances concernant la reconnaissance et la revalorisation des privilèges.

Dans ce contexte, comment mettre en valeur les tableaux ? Les portraits sont-ils déposés dans des endroits particuliers qui leur confèrent une signification particulière? 